\title{
Modeling of Coupled Thermo-Hydro-Mechanical Processes with Links to Geochemistry Associated with Bentonite-Backfilled Repository Tunnels in Clay Formations
}

\author{
Jonny Rutqvist $\cdot$ Liange Zheng $\cdot$ Fei Chen $\cdot$ \\ Hui-Hai Liu $\cdot$ Jens Birkholzer
}

Received: 11 January 2013/Accepted: 14 January 2013/Published online: 16 March 2013

(c) The Author(s) 2013. This article is published with open access at Springerlink.com

\begin{abstract}
This paper presents simulation results related to coupled thermal-hydraulic-mechanical (THM) processes in engineered barrier systems (EBS) and clay host rock, in one case considering a possible link to geochemistry. This study is part of the US DOE Office of Nuclear Energy's used fuel disposition campaign, to investigate current modeling capabilities and to identify issues and knowledge gaps associated with coupled THMC processes and EBSrock interactions associated with repositories hosted in clay rock. In this study, we simulated a generic repository case assuming an EBS design with waste emplacement in horizontal tunnels that are back-filled with bentonite-based swelling clay as a protective buffer and heat load, derived for one type of US reactor spent fuel. We adopted the Barcelona basic model (BBM) for modeling of the geomechanical behavior of the bentonite, using properties corresponding to the FEBEX bentonite, and we used clay host rock properties derived from the Opalinus clay at Mont Terri, Switzerland. We present results related to EBS host-rock interactions and geomechanical performance in general, as well as studies related to peak temperature, buffer resaturation and thermally induced pressurization of host rock pore water, and swelling pressure change owing to variation of chemical composition in the EBS. Our initial THM modeling results show strong THM-driven interactions between the bentonite buffer and the lowpermeability host rock. The resaturation of the buffer is delayed as a result of the low rock permeability, and the fluid pressure in the host rock is strongly coupled with the temperature changes, which under certain circumstances
\end{abstract}

J. Rutqvist $(\bowtie) \cdot$ L. Zheng · F. Chen · H.-H. Liu · J. Birkholzer Lawrence Berkeley National Laboratory (LBNL),

Berkeley, CA 94720, USA

e-mail: Jrutqvist@lbl.goc could result in a significant increase in pore pressure. Moreover, using the BBM, the bentonite buffer was found to have a rather complex geomechanical behavior that eventually leads to a slightly nonuniform density distribution. Nevertheless, the simulation shows that the swelling of the buffer is functioning to provide an adequate increase in confining stress on the tunnel wall, leading to a stabilization of any failure that may occur during the tunnel excavation. Finally, we describe the application of a possible approach for linking THM processes with chemistry, focusing on the evolution of primary and secondary swelling, in which the secondary swelling is caused by changes in ionic concentration, which in turn is evaluated using a transport simulation model.

Keywords Nuclear waste disposal · Modeling . Coupled processes · Geomechanics - Geochemistry · Clay $\cdot$ Shale $\cdot$ Bentonite

\section{Introduction}

Clay/shale has been considered as potential host rock for geological disposal of high-level nuclear waste throughout the world, because of its low permeability, low diffusion coefficient, high retention capacity for radionuclides, and capability for self-sealing fractures induced by tunnel excavation. For example, Callovo-Oxfordian argillites at the Bure site, France (Fouché et al. 2004), Toarcian argillites at the Tournemire site, France (Patriarche et al. 2004), Opalinus clay at the Mont Terri site, Switzerland (Meier et al. 2000), and Boom clay at the Mol site, Belgium (Barnichon and Volckaert 2003), have all been under intensive scientific investigation (at both field and laboratory scales) for understanding a variety of rock 
properties and their relationships to flow and transport processes associated with geological disposal of nuclear waste. Clay/shale formations may be generally classified as indurated or plastic clays. Plastic clays (including Boom clay) are a softer material without high cohesion and deformation is dominantly plastic.

In the US, research and development efforts regarding potential shale repositories investigations had already been undertaken from the 1970s and continued into the mid1980s, led by the Oak Ridge National Laboratory (ORNL) (Hansen et al. 2010). A substantial review of shale and argillaceous formations in the US was conducted (Gonzales and Johnson 1984) before the nuclear waste program was directed to focus solely on characterizing Yucca Mountain. In fact, the US has many possible clay/shale/argillite basins with positive attributes for permanent disposal. (Gonzales and Johnson 1984) concluded that the most desirable host rock should be between 300 and $900 \mathrm{~m}$ below ground level, at least $75 \mathrm{~m}$ thick, relatively homogeneous in composition, and in an area of low seismicity and favorable hydrology (and not likely to be intensively exploited for subsurface resources) (Hansen et al. 2010). Figure 1 is a map of the US showing distribution of principal shale formations by general geologic age and regions, for which broad geologic and hydrologic data were reviewed by (Gonzales and Johnson 1984). Recently, Hansen et al. (2010) presented a feasibility study, indicating that shale formations provide a technically advanced, scientifically sound disposal option for the US.

This paper presents simulation results related to coupled thermal, hydrogeological, mechanical, and chemical (THMC) processes in the engineered barrier system (EBS) and near-field rock associated with high-level radioactive waste repositories hosted in clay formations. The study is part of the research and development portfolio of the US Department of Energy's used fuel disposition (UFD) campaign. The UFD campaign was initiated in 2009 to evaluate and improve upon the technical basis for highlevel nuclear waste disposal in host rocks such as crystalline, clay, and salt formations. During the lifespan of a clay repository, the repository performance is affected by complex THMC processes, such as heat release due to radionuclide decay, multiphase flow, formation of damage zones, radionuclide transport, waste dissolution, and chemical reactions. All these processes are related to each other. An in-depth understanding of these coupled processes is critical for the performance assessment (PA) of the repository. These coupled processes may affect radionuclide transport by changing transport paths (e.g., evolution of excavation damaged zone-EDZ) and altering flow, mineral, and mechanical properties related to radionuclide transport. The work presented here is part of an initial study within the UDF to investigate current modeling capabilities and to identify issues and knowledge gaps associated with coupled THMC processes and EBS-rock interactions.

In this study, we simulate a generic repository case assuming an EBS design with waste emplacement in horizontal tunnels back-filled with bentonite-based swelling clay as a protective buffer (Fig. 2). In the model simulations, we use clay host rock properties derived from the Opalinus clay at Mont Terri, Switzerland (Gens et al. 2007) and adopt a heat load developed within the UFD as a generic disposal system environment (GDSE) for pressurized water reactor (PWR) used nuclear fuel. The THM model simulation is conducted with TOUGH-FLAC, a coupled multiphase flow and geomechanics simulator that has previously been applied extensively for modeling
Fig. 1 Clay/shale provinces in the United States (Gonzales and Johnson 1984)

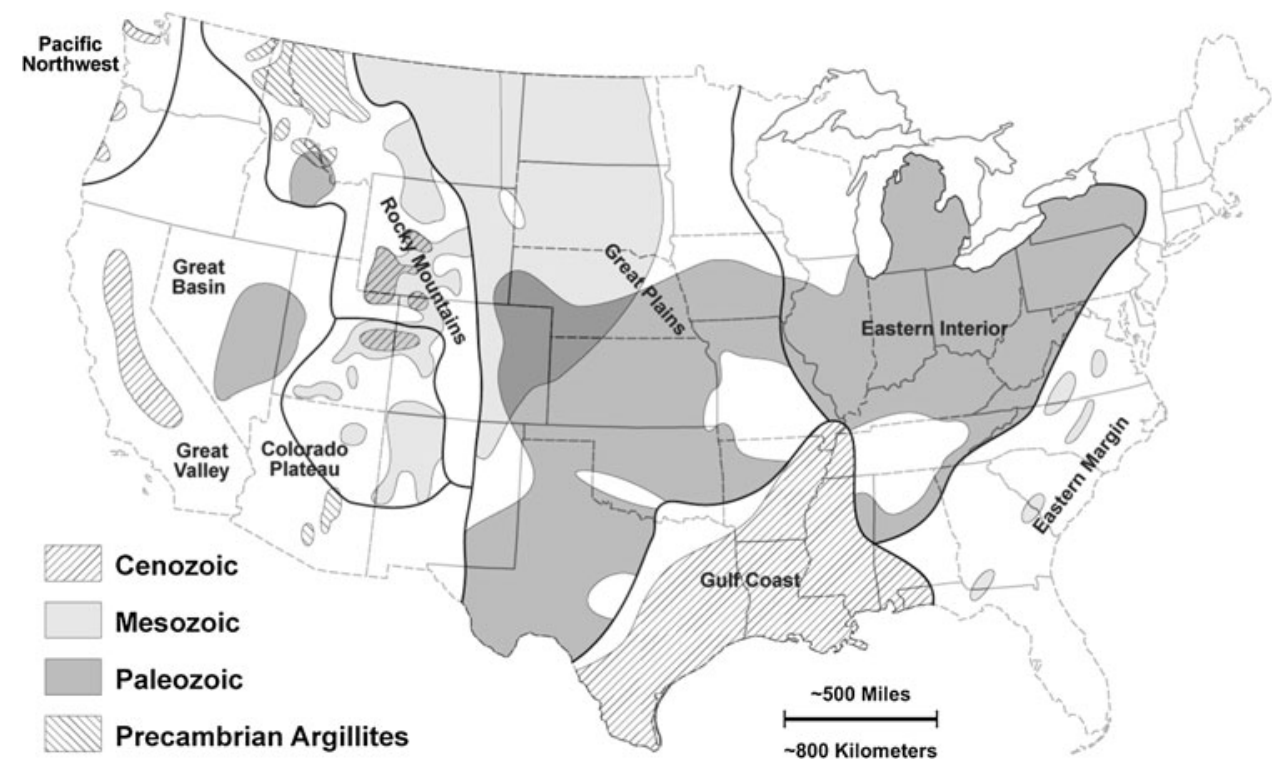


thermally driven coupled processes in volcanic tuff at Yucca Mountain, but is now being modified for modeling systems involving bentonite-backfilled nuclear waste deposition tunnels in clay host rock (Rutqvist et al. 2002; Rutqvist 2011). The TOUGH-FLAC simulator is based on linking the TOUGH2 multiphase flow and heat transport simulator (Pruess et al. 2011) with the FLAC3D geomechanical simulator (ITASCA 2009).

One recent important development was the implementation of the Barcelona basic model (BBM) (Alonso et al. 1990; Gens et al. 2006) into TOUGH-FLAC for modeling of the geomechanical behavior of bentonite (Rutqvist et al. 2011). The BBM was first developed and presented in the early 1990s as an extension of the modified Cam clay (MCC) model to unsaturated soil conditions (Alonso et al. 1990). The model can describe many typical features of unsaturated-soil mechanical behavior, including wettinginduced swelling or collapse strains, depending on the magnitude of applied stress, as well as the increase in shear strength and apparent pre-consolidation stress with suction (Gens et al. 2006). The BBM has been used for modeling of bentonite buffer behavior in various national nuclear waste programs in Europe and Japan. For example, the BBM was recently successfully applied to model the coupled thermal-hydrological-mechanical (THM) behavior of unsaturated bentonite clay associated with the FEBEX in situ heater test at the Grimsel test site, Switzerland (Gens et al. 2009). The BBM has also been applied to other types of bentonite-sand mixtures based on MX-80, considered as an option for an isolating buffer in the Swedish KBS-3

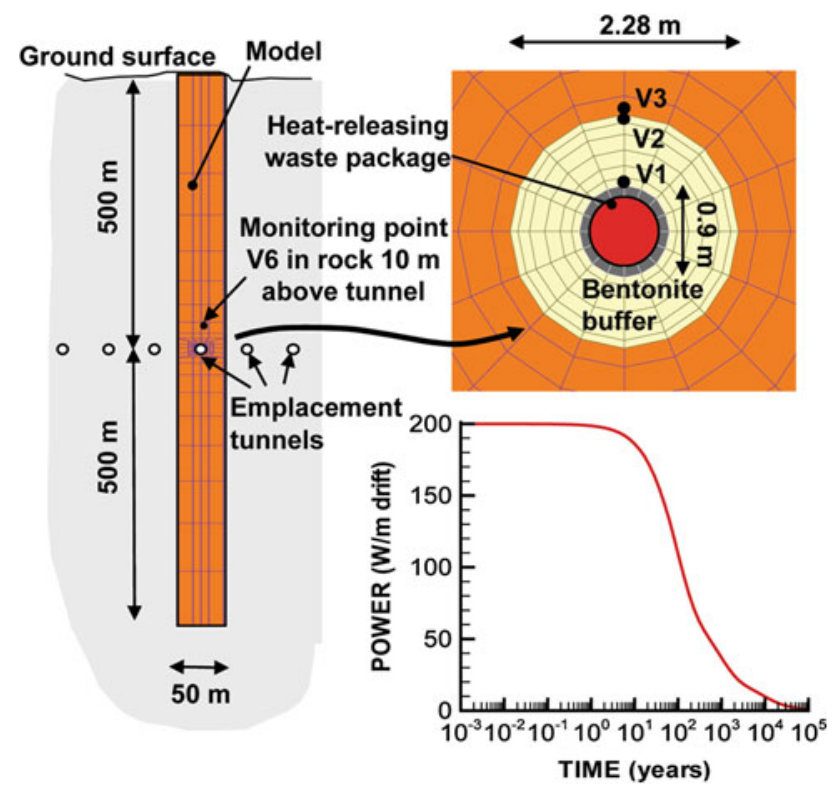

Fig. 2 Model domain, numerical grid, monitoring points and heat power function for an assumed bentonite-backfilled horizontal emplacement drift at $500 \mathrm{~m}$ depth in clay host rock repository concept (Kristensson and Åkesson 2008). In the simulations presented in this paper, we use the BBM for modeling of the bentonite buffer with properties derived from laboratory measurements and the FEBEX full scale, in situ EBS experiment at Grimsel, Switzerland (Alonso et al. 2005; Gens et al. 2009). Moreover, we apply an anisotropic elasto-plastic mechanical model for the Opalinus clay, in which shear strength is lower along bedding planes. Thus, the TOUGH-FLAC simulator is used to model coupled THM processes in the buffer and host rock, as well as buffer/host rock interactions.

The simulations include a complete sequence of excavation, emplacement of waste, and backfill, followed by 100,000 years of post-closure. We study the evolution of temperature, fluid pressure, saturation, and stress to evaluate the coupled geomechanical performance of the repository, and pay particular attention to a number of performance indicators such as peak temperature, resaturation time, and peak stress. Finally, we also present a simulation case in which we extend our analysis to consider chemical effects on the buffer stress evolution (i.e., including both primary and secondary swelling, in which the secondary swelling is caused by chemical interactions). In such cases the numerical simulations are conducted linking the reactive transport simulator TOUGHREACT (Xu et al. 2011) to FLAC3D. Currently there are also other codes that have some THMC capability such as CODE_ BRIGHT (Guimarães et al. 2007) and FADES-CORE (Zheng and Samper 2008) and have been used to conduct THMC simulations (e.g., Gens et al. 2010; Zheng et al. 2010). However, in these simulations, while they demonstrated that THMC simulations can be done by one code simultaneously, how chemical and mechanical processes were coupled was not discussed. In this paper, after equipped with THMC capability, we consider the coupling of chemical and mechanical processes with a simple coupling relation to evaluate the effect of concentration changes on stress and we limit our chemical analysis to conservative transport.

\section{Thermal-Elasto-Plastic BBM in TOUGH-FLAC}

We provide a brief description of the thermo-elasto-plastic BBM and TOUGH-FLAC for modeling of bentonite behavior. The description follows that of Rutqvist et al. (2011), but focusing on the most relevant features for this study. The thermo-elasto-plastic version of the BBM implemented into TOUGH-FLAC is not the original BBM (Alonso et al. 1990), but is an extension in which the soil strength depends on both suction and temperature, and includes features for expansive (swelling) clay (Gens 1995). 


\subsection{Three-Dimensional Yield Surface}

Figure 3 presents the three-dimensional yield surface in $p^{\prime}$ $q-s$ space and $p^{\prime}-q-T$ space, where $p^{\prime}$ is net mean stress (i.e., total stress minus gas-phase pressure), $q$ is deviatoric stress (or shear stress), $s$ is suction, and $T$ is temperature (Gens 1995). Under water-saturated conditions $(s=0)$, the yield surface corresponds to the MCC ellipse (Roscoe and Burland 1968), and the size of the elastic domain increases as suction increases. The rate of increase, represented by the loading collapse (LC) curve, is one of the fundamental characteristics of the BBM (Gens et al. 2006). Moreover, in the thermo-elasto-plastic version of the BBM, the size of the yield surface decreases with temperature (Fig. 3). In Rutqvist et al. (2011), the implementation of BBM into TOUGH-FLAC is described as (1) the extension of an existing MCC module within the framework of the FLAC3D user defined model (UDM) capability, and (2) the addition of computational routines for suction-dependent strains and net stress in unsaturated soils.

\subsection{Stress State}

We remind that the conventional (Terzaghi) effective stress that can be expressed as

$\sigma^{\prime}=\sigma-p^{\phi} \mathrm{I}$

where $\boldsymbol{\sigma}^{\prime}$ and $\boldsymbol{\sigma}$ are, respectively, the effective and total stress tensors (positive for compression), $p^{\phi}$ is pore pressure, and $\mathbf{I}$ is the identity tensor. The stress state can be divided into a hydrostatic part (1/3)trace $\left(\boldsymbol{\sigma}^{\prime}\right) \mathbf{I}=p^{\prime} \mathbf{I}$ and deviatoric part $\mathbf{s}=\boldsymbol{\sigma}^{\prime}-p^{\prime} \mathbf{I}$, where $p^{\prime}$ is the effective mean pressure (or effective mean stress) that can be expressed explicitly as:

$p^{\prime}=p-p^{\phi}=\frac{1}{3}\left(\sigma_{1}+\sigma_{2}+\sigma_{3}\right)-p^{\phi}$ where $p$ is total mean pressure (total mean stress), and $\sigma_{1}, \sigma_{2}$, and $\sigma_{3}$ are principal compressive stresses. The conventional effective mean stress is used for watersaturated conditions as in the modified Cam clay (MCC) model (Roscoe and Burland 1968). In the BBM, however, under unsaturated conditions, the strains are related to changes in two independent stress variables, namely the net mean stress for which

$p^{\prime}=p-p^{\mathrm{g}}$

and suction, $s$, is defined as

$s=p^{\mathrm{g}}-p^{1}$

where $p^{\mathrm{g}}$ and $p^{1}$ are gas- and liquid-phase pressures.

The deviatoric (von Mises) stress, $q$, is defined as:

$$
\begin{aligned}
q & =\sqrt{3 J_{2}}=\sqrt{3 \frac{1}{2} \mathrm{~s} \cdot \mathrm{s}} \\
& =\sqrt{\frac{\left(\sigma_{1}^{\prime}-\sigma_{2}^{\prime}\right)^{2}+\left(\sigma_{2}^{\prime}-\sigma_{3}^{\prime}\right)^{2}+\left(\sigma_{1}^{\prime}-\sigma_{3}^{\prime}\right)^{2}}{2}}
\end{aligned}
$$

where $J_{2}$ is the second invariant of the effective deviatoricstress tensor, $\mathbf{s}$.

The suction, $s$, is calculated from the TOUGH2 capillary pressure, which in turn is calculated from gas- and liquidphase pressures according to Eq. (4). Moreover, in TOUGH-FLAC, the concept of net mean stress for unsaturated soils is implemented by transferring the maximum of the gas- or liquid-phase pressure from TOUGH to FLAC3D according to

$p^{\phi}=\operatorname{MAX}\left(p^{1}, p^{\mathrm{g}}\right)$.

This approach enables simulation of both saturated and unsaturated soils. Under single-fluid phase conditions, the first primary variable is $p^{\mathrm{g}}$ for single gas phase or $p^{1}$ for single liquid phase. For two fluid phase conditions, the primary variable is gas pressure, which is greater than the
Fig. 3 Three-dimensional representation of the yield surface in the thermo-elastoplastic BBM (Gens 1995)

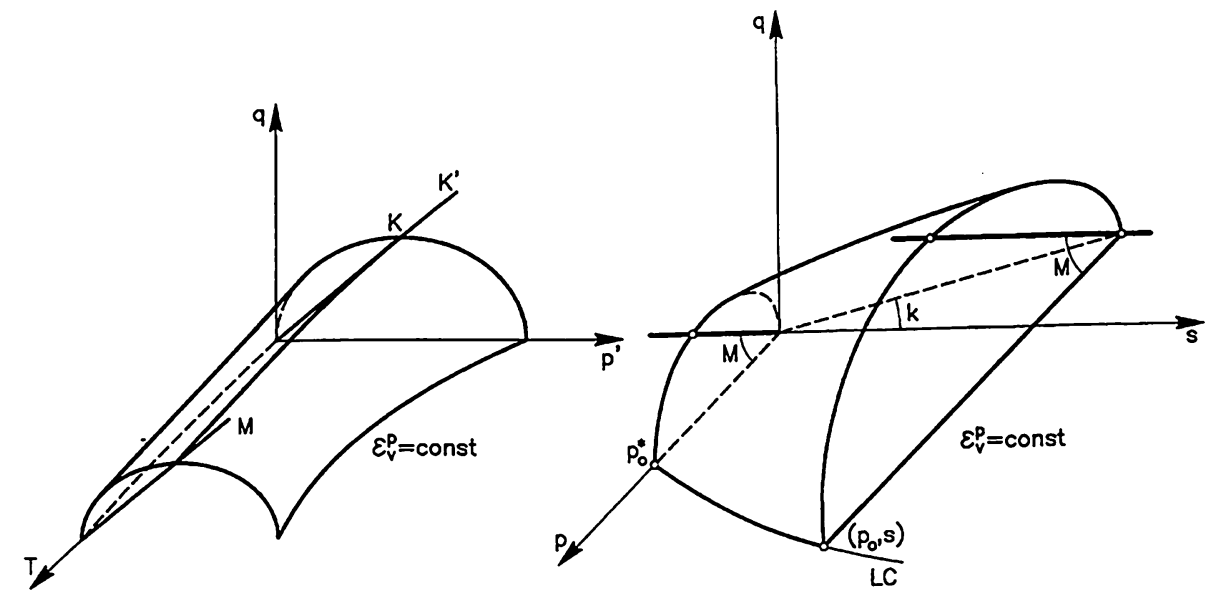


liquid pressure. As a result, for fully liquid saturated conditions, the conventional effective stress applies according to Eq. (2), whereas for unsaturated conditions, the mechanical behavior depends on the two stress variables net stress and suction, defined in Eqs. (3) and (4).

\subsection{Strains Due to Stress, Temperature and Suction}

The strain tensor can-similarly to the stress tensor-be expressed as the sum of a hydrostatic part (1/3)tra$\operatorname{ce}(\boldsymbol{\varepsilon}) \mathbf{I}=(1 / 3) \varepsilon_{\mathrm{v}} \mathbf{I}$ and deviatoric part $\mathbf{e}=\boldsymbol{\varepsilon}-(1 / 3) \varepsilon_{\mathrm{v}} \mathbf{I}$, where $\varepsilon_{\mathrm{v}}$ is the volumetric strain associated with change in net mean stress, $p^{\prime}$, and can be explicitly expressed as

$\varepsilon_{v}=\left(\varepsilon_{1}+\varepsilon_{2}+\varepsilon_{3}\right)$

where $\varepsilon_{1}, \varepsilon_{2}$, and $\varepsilon_{3}$ are principal strains.

An equivalent deviatoric strain, associated with distortion and changes in deviatoric stress $q$, may be defined as:

$$
\begin{aligned}
\varepsilon_{q} & =\frac{2}{3} \sqrt{3 J_{2}^{\prime}}=\frac{2}{3} \sqrt{3 \frac{1}{2} e \cdot e} \\
& =\frac{2}{\sqrt{6}} \sqrt{\left(\varepsilon_{1}-\varepsilon_{2}\right)^{2}+\left(\varepsilon_{2}-\varepsilon_{3}\right)^{2}+\left(\varepsilon_{3}-\varepsilon_{1}\right)^{2}}
\end{aligned}
$$

where $J^{\prime}{ }_{2}$ stands for stands for the second invariant of the deviatoric-strain tensor $\mathbf{e}$.

For nonisothermal behavior of unsaturated soils, we may partition the total incremental strain into elastic, plastic, suction, and thermal strains:

$d \varepsilon=d \varepsilon^{e}+d \varepsilon^{p}+d \varepsilon^{s}+d \varepsilon^{T}$

where the suction strain represents the strain associated with changes in suction. Each of these types of strain are described in the following subsections.

\subsubsection{Elastic Strain}

The mechanical volumetric elastic strain increment is associated with changes in net mean stress $\mathrm{d} p^{\prime}$ according to

$d \varepsilon_{v}^{e}=\frac{1}{K} d p^{\prime}$

where the bulk modulus $K$ is defined as

$K=\frac{(1+e) p^{\prime}}{\kappa_{p s}(s)}$

in which the compressibility function $\kappa_{p s}(s)$ is defined empirically as

$\kappa_{p s}(s)=\kappa_{p s 0}\left[1+s \alpha_{p s}\right]$

and thus $\kappa_{p s o}$ and $\alpha_{p s}$ are empirical material constants.

The deviatoric elastic strain increment is defined as

$d \varepsilon_{q}^{e}=\frac{1}{3 G} d q$ where $G$ may be obtained using a constant Poisson's ratio $v$ in

$G=\frac{3(1-2 v)}{2(1+v)} K$

Thus, the equations for elastic mechanical strain indicate the dependency of bulk modulus on suction (and hence fluid saturation) in which dry clay can be significantly stiffer than water-saturated clay.

\subsubsection{Plastic Strain}

The temperature- and suction-dependent loading collapse (LC) yield surface (Fig. 3) bounds the elastic region according to

$f_{L C}=\frac{q^{2}}{g_{y}(\theta)^{2}}-\frac{M^{2}}{g_{y}(\theta=0)^{2}}\left(p^{\prime}+p_{s}(s, T)\right)\left(p_{0}(s, T)-p^{\prime}\right)=0$

where $\theta$ is the Lode's angle, and the function $g_{y}(\theta)$ describes the shape of the yield surface in the deviatoric plane. $M$ is the constant slope of the critical state line (Fig. 3), whereas

$p_{s}(s, T)=p_{s 0}+k_{s} s \exp \left[-\rho_{s} \Delta T\right]$

represents the increases in cohesion with suction and temperature change $\Delta T$, where $k_{s}$ and $\rho_{s}$ are empirical material constants.

In Eq. (15), the function

$p_{0}(s, T)=p^{c}\left(\frac{p_{0 T}^{*}(T)}{p^{c}}\right)^{\left[\lambda_{P s 0}-\kappa_{P s 0}\right] /\left[\lambda_{P_{s}}-\kappa P_{s 0}\right]}$

is the net mean yield stress (or apparent pre-consolidation stress) at current suction and temperature, where

$P_{0 T}^{*}(T)=P_{0}^{*}+2\left(\alpha_{1} \Delta T+\alpha_{3} \Delta T|\Delta T|\right)$

is the temperature-dependent net mean yield stress (or preconsolidation stress) at full saturation and

$\lambda_{P S}(s)=\lambda_{P S 0}\left(\left(1-r_{\lambda}\right) \exp \left(-\beta_{\lambda} s\right)+r_{\lambda}\right)$

is a compressibility parameter in virgin soil states at suction $s$. Equation (18) is discussed in (Gens 1995) considering a suction-dependent thermoelastic energy potential that results in a decrease of the pre-consolidation stress $p_{0 T}^{*}(T)$ and an associated reduction of the yield surface with temperature (Fig. 3). Equation (19) is yet another empirical relationship in which $\lambda_{P s}$ determines the shape of the LC yield surface, which increases in size with suction (Fig. 3).

When the stress state is on the yield surface, the plastic strains are obtained from the plastic flow rule 
$\mathrm{d} \varepsilon_{P}^{P}=\mathrm{d} \Lambda \frac{\partial g}{\partial p}$

$d \varepsilon_{q}^{P}=d \Lambda \frac{\partial g}{\partial q}$

where $d \Lambda$ is the plastic multiplier obtained from the consistency condition $d f_{L C}=0$, and $g_{L C}$ is the plastic potential defined by

$g_{L C}=\frac{\alpha_{a} q^{2}}{g_{y}(\theta)^{2}}-\frac{M^{2}}{g_{y}(\theta=0)^{2}}\left(p^{\prime}+p_{s}(s, T)\right)\left(P_{0}\left(p_{0}^{*}, s\right)-p^{\prime}\right)$

where $\alpha_{a}$ is a parameter that gives rise to the nonassociative model, i.e., $g_{L C} \neq f_{L C}$. The calculation of the plastic multiplier $d \Lambda$ is described in (Rutqvist et al. 2011).

\subsubsection{Thermal Strain}

Thermally induced strains are purely volumetric:

$d \varepsilon_{v}^{T}=\left(\alpha_{0}+2 \alpha_{2} \Delta T\right) d T$

where $\alpha_{0}$ and $\alpha_{2}$ are material parameters corresponding to a temperature-dependent volumetric thermal expansion coefficient.

\subsubsection{Suction Strain}

In analogy with thermally induced strains, the suction strain is purely volumetric:

$d \varepsilon_{v}^{s}=\frac{1}{K^{s}} d s$

in which $K^{s}$ the suction bulk modulus

$K^{s}=\frac{(1+e)\left(s+p_{a t m}\right)}{\kappa_{s p}\left(p^{\prime}, s\right)}$

where $\kappa_{S P}$ is a compressibility parameter for suctioninduced strain defined as

$\kappa_{s p}\left(p^{\prime}, s\right)=\kappa_{s p 0}\left(1+\alpha_{s p} \ln \frac{p^{\prime}}{P_{\text {ref }}}\right) \exp \left(\alpha_{s s} s\right)$

which is a purely empirical relation that is determined by matching the observed swellings at different applied stresses and suctions.

\section{THM Model Setup and Simulation Sequence}

For our generic-model-simulation example, we chose a repository design similar to the one considered in the Swiss nuclear waste disposal program, with the repository located at a depth of $500 \mathrm{~m}$ in Opalinus clay and with the bedding planes of the Opalinus clay being horizontal. The heat load for a waste package and spacing of individual emplacement tunnels are both important for peak temperature, a common performance indicator. In repository designs with bentonite-backfilled repository tunnels, the PWR type of used fuel is typically packed into a waste package (or canister) with dimensions of about $1 \mathrm{~m}$ in diameter and about $5 \mathrm{~m}$ long, as dictated by the length of individual PWR fuel elements and the number of fuel assemblies per waste package. An assembly of four PWR assemblies per waste package is commonly adopted for bentonite-backfilled repositories in various kinds of host rock, including crystalline and clay (e.g., Swedish, Finish, Swiss, and Spanish proposed repository designs). Moreover, the emplacement tunnels may typically be up to $1 \mathrm{~km}$ long.

The basic material parameters used for the base-case simulation scenario are presented in Tables 1, 2 and 3. As mentioned above, the bentonite properties, including thermal and hydraulic properties (Table 1) and BBM parameters (Table 2), were derived from laboratory experiments and in situ tests of FEBEX bentonite (Alonso et al. 2005; Gens et al. 2009). The material parameters for bentonite in Tables 1 and 2, including those related to the BBM are explained in Rutqvist et al. (2011). Among the thermalhydrological parameters presented in Table 1 , the retention curve governed by the van Genuchten function is particularly important. Similarly to Gens et al. (2009), we neglect potential effects of temperature and hysteresis on the retention curves. We account for changes in the retention

Table 1 Thermal and hydraulic properties of the bentonite buffer (Gens et al. 2009)

\begin{tabular}{ll}
\hline Parameter & Value/function \\
\hline $\begin{array}{l}\text { Initial dry density, } \\
\rho_{\mathrm{d}}\left(\mathrm{kg} / \mathrm{m}^{3}\right)\end{array}$ & $1.6 \cdot 10^{3}$ \\
Initial porosity, $\phi(-)$ & 0.41 \\
Saturated permeability, & $2.0 \cdot 10^{-21}$ \\
$\quad k\left(\mathrm{~m}^{2}\right)$ & \\
Relative permeability, $k_{\mathrm{r}}(-)$ & $k_{\mathrm{rl}}=S_{\mathrm{l}}^{3}$ \\
Van Genuchten parameter, & 30 \\
$\quad P_{\mathrm{VG}}(\mathrm{MPa})$ & \\
$\left(\begin{array}{l}\text { van Genuchten } 1980) \\
\text { parameter, } \lambda_{\mathrm{VG}}(-)\end{array}\right.$ & 0.32 \\
Thermal expansion, & $1.5 \times 10^{-4}$ \\
$\quad \beta\left(1 /{ }^{\circ} \mathrm{C}\right)$ & \\
Dry specific heat, & $c_{\mathrm{S}}=1.38 \mathrm{~T}+732.5$ \\
$C_{\mathrm{s}}\left(\mathrm{J} / \mathrm{kg}{ }^{\circ} \mathrm{C}\right)$ & \\
Thermal conductivity, & $\lambda_{\mathrm{m}}=1.28-\frac{0.71}{1+e^{\left(S_{\mathrm{s}}-0.65\right) / 0.1}}$ \\
$\lambda_{\mathrm{m}}(\mathrm{W} / \mathrm{mK})$ & \\
Effective molecular & $D_{\mathrm{v}}=2.16 e-5 \times \tau \times \varphi \times S_{\mathrm{g}}\left(\frac{T_{\mathrm{abs}}}{273.8}\right)$ \\
$\quad$ diffusion coefficient, & \\
$D_{\mathrm{v}}\left(\mathrm{m}^{2} / \mathrm{s}\right)$ & \\
Mass flow times tortuosity & 0.8 \\
factor, $\tau(-)$ & \\
\hline
\end{tabular}


Table 2 BBM material parameter values for the bentonite buffer (Gens et al. 2009)

\begin{tabular}{|c|c|}
\hline Parameter & Value \\
\hline $\begin{array}{l}\text { Compressibility parameter for stress-induced elastic } \\
\text { strain, } \kappa_{\mathrm{PS} 0}(-)\end{array}$ & 0.05 \\
\hline $\begin{array}{l}\text { Compressibility parameter for suction-induced elastic } \\
\text { strain, } \kappa_{\mathrm{SP} 0}(-)\end{array}$ & 0.25 \\
\hline Shear modulus, $G(\mathrm{MPa})$ & NA \\
\hline Poisson's ratio, $v(-)$ & 0.4 \\
\hline Parameter for suction-induced elastic strain, $\alpha_{S S}(-)$ & 0 \\
\hline Parameter for stress-induced strain $\alpha_{\mathrm{PS}}\left(\mathrm{MPa}^{-1}\right)$ & -0.003 \\
\hline Parameter for stress-induced strain, $\alpha_{\mathrm{SP}}(-)$ & -0.161 \\
\hline $\begin{array}{l}\text { Reference stress state for relating elastic compressibility } \\
\text { to suction, } P_{\text {ref }}(\mathrm{MPa})\end{array}$ & 0.5 \\
\hline $\begin{array}{l}\text { Parameters that relate elastic volumetric strain and } \\
\text { temperature changes, } \alpha_{0}\left({ }^{\circ} \mathrm{C}^{-1}\right)\end{array}$ & $1.5 \mathrm{e}-4$ \\
\hline $\begin{array}{l}\text { Compressibility parameter in virgin soil states at zero } \\
\text { suction, } \lambda_{\mathrm{PS} 0}(-)\end{array}$ & 0.15 \\
\hline $\begin{array}{l}\text { Parameter defining soil stiffness associated with loading } \\
\text { collapse yield, } r_{\lambda}(-)\end{array}$ & 0.925 \\
\hline $\begin{array}{l}\text { Parameter for the increase of soil stiffness with suction, } \beta_{\lambda} \\
\left(\mathrm{MPa}^{-1}\right)\end{array}$ & 0.1 \\
\hline Parameter that relates cohesion to temperature, $\rho_{\mathrm{s}}\left({ }^{\circ} \mathrm{C}^{-1}\right)$ & 0 \\
\hline $\begin{array}{l}\text { Parameter describing the increase of cohesion with } \\
\text { suction, } k_{\mathrm{s}}(-)\end{array}$ & 0.1 \\
\hline Tensile strength at saturated conditions, $P_{\mathrm{S} 0}(\mathrm{MPa})$ & 0 \\
\hline $\begin{array}{l}\text { A reference stress state for compressibility relation in } \\
\text { virgin states, } P^{\mathrm{C}}(\mathrm{MPa})\end{array}$ & 0.5 \\
\hline Slope of the critical state line, $M(-)$ & 1 \\
\hline $\begin{array}{l}\text { Nonassociativity parameter in the plasticity flow rule, } \\
\alpha_{\mathrm{a}}(-)\end{array}$ & 0.53 \\
\hline $\begin{array}{l}\text { Specific volume at reference stress states } P^{\mathrm{C}} \text { in virgin } \\
\text { states, } v^{\mathrm{c}}(-)\end{array}$ & 1.937 \\
\hline $\begin{array}{l}\text { Net mean yield stress for saturated conditions at reference } \\
\text { temperature, } P_{0 \mathrm{~T}}^{*}(\mathrm{MPa})\end{array}$ & 12.0 \\
\hline
\end{tabular}

curve with changes in the skeleton through a simple Leveret scaling with porosity as described in (Rutqvist et al. 2002), whereas (in this study) we do not account for changes in absolute permeability with porosity. A possibility would be to use a simple porosity versus permeability function described in Gens et al. (2009) and this would be expected to impact the resaturation of the buffer.

In a parameter study, we are also considering other options for the bentonite buffer, such as bentonite pellets (in which the initial saturation is lower), which would have a significant effect on the THM evolution in the buffer.

The rock properties in Table 3 correspond to that of Opalinus clay, with values taken from Gens et al. (2007) as well as Corkum and Martin (2007). Here, we utilize the FLAC3D ubiquitous joint model, a model also used by Corkum and Martin (2007) when simulating previous in situ experiments in Opalinus clay at Mont Terri. The
Table 3 THM rock properties for the clay stone host rock (Gens et al. 2007; Corkum and Martin 2007)

\begin{tabular}{ll}
\hline Parameter & Value \\
\hline Bulk density $\left(\mathrm{kg} / \mathrm{m}^{3}\right)$ & 2,400 \\
Matrix porosity $(-)$ & 0.15 \\
Young's modulus $(\mathrm{GPa})$ & 5 \\
Poisson's ratio $(-)$ & 0.3 \\
Specific heat $\left(\mathrm{J} / \mathrm{kg}{ }^{\circ} \mathrm{C}\right)$ & 900 \\
Thermal conductivity $(\mathrm{W} / \mathrm{mK})$ & 2.2 \\
Thermal expansion coefficient $\left({ }^{\circ} \mathrm{C}^{-1}\right)$ & $1.0 \times 10^{-5}$ \\
Permeability $\left(\mathrm{m}^{2}\right)$ & $5.0 \times 10^{-20}$ \\
Biot's effective stress parameter & 1.0 \\
Van Genuchten water retention parameter, $m$ & 0.41 \\
Van Genuchten water retention parameter, $P_{0}(\mathrm{MPa})$ & 48 \\
Bulk modulus, $K(\mathrm{GPa})$ & 4.17 \\
Shear modulus, $G(\mathrm{GPa})$ & 1.92 \\
Cohesion, $C(\mathrm{MPa})$ & 5 \\
Friction angle $\left({ }^{\circ}\right)$ & $25^{\circ}$ \\
Dilation angle $\left({ }^{\circ}\right)$ & $10^{\circ}$ \\
Tensile strength $(\mathrm{MPa})$ & 1.0 \\
Joint cohesion $(\mathrm{MPa})$ & 2.2 \\
Joint friction $\left({ }^{\circ}\right)$ & $23^{\circ}$ \\
Joint tensile strength $(\mathrm{MPa})$ & 0.5 \\
\hline
\end{tabular}

theory and implementation of this model in FLAC3D is described in the FLAC3D manual (ITASCA 2009). The model accounts for the presence of an orientation of weakness (weak plane) in a Mohr-Coulomb model. The criterion for failure on the plane, whose orientation is given, consists of a composite Mohr-Coulomb envelope with tension cutoff. Thus, rock-strength input parameters given in Table 3 includes friction angle and tension cutoff with weaker properties for the weak (joint) planes compared to that of the intermediate intact rock. As mentioned, the beddings in the Opalinus clay are here assumed horizontal since the entire repository having a footprint of several square kilometers should be hosted in an Opalinus layer that might be $150 \mathrm{~m}$ thick. In our initial base-case simulation, we assume that geological layers above and below the Opalinus have the same properties; other scenarios are tested in sensitivity studies. Finally, a Terzaghi effective stress law is adopted for the rock, i.e., Biot's coefficient is set to 1.0 .

The simulations are conducted in a $2 \mathrm{D}$ plane strain model as shown in Fig. 2. Because of the repetitive later symmetry, the model extends horizontally to the mid-distance between two emplacement tunnels. In the 2D model, we scale the heat load and apply a line load per meter tunnel. The simulation results would thus represent a repository emplacement tunnel somewhere towards the middle of the repository assuming simultaneous 
emplacement in neighboring emplacement tunnels. Considering an initial thermal power of $3,144 \mathrm{~W}$ for a 4-PWRelement waste package, surface waste deposition of 60 years, a 50-m spacing between emplacement tunnels, and spacing between the 5-m-long packages back-analyzed such that temperature would not rise above $100{ }^{\circ} \mathrm{C}$ (equal to $3 \mathrm{~m}$ ), the average thermal power per meter drift was found to be equal to $200 \mathrm{~W}$. The final model dimensions and heat decay curve for these conditions are presented in Fig. 2 and serve as a base case in our model simulations.

Figure 4 presents the detailed modeling sequence, as well as boundary and initial conditions for the coupled THM simulation. The initial conditions for the rock mass were established at the pre-excavation stage (Fig. 4a). Initial stress was set as $\sigma_{\mathrm{h}}=\sigma_{\mathrm{H}}=\sigma_{\mathrm{V}}=2400 \bullet 9.81 \bullet \mathrm{D}$ where
$\mathrm{D}$ is elevation relative to ground surface $(\mathrm{D}=\mathrm{z}-500$ and tensile stress is positive). Thus, at the depth of the emplacement tunnel $(500 \mathrm{~m})$, the initial stress is $-11.8 \mathrm{MPa}$. The vertical temperature gradient is assumed to be $30{ }^{\circ} \mathrm{C} / \mathrm{km}$ with a fixed average temperature of $10^{\circ} \mathrm{C}$ on the ground surface and a fixed temperature of $40{ }^{\circ} \mathrm{C}$ at the bottom boundary. The groundwater table is assumed to be located at the ground surface where the pressure is fixed to $0.1 \mathrm{MPa}$ (atmospheric). At the bottom of the model, the fluid pressure is set to $9 \mathrm{MPa}$, which is slightly less than hydrostatic. The excavation sequence was simulated in a one-step steady-state calculation, with the elements in the drift removed and a constant temperature of $25^{\circ} \mathrm{C}$ and pressure of $0.1 \mathrm{MPa}$ at the drift boundary (Fig. 4b). After the steady-state excavation simulation was completed, the
Fig. 4 Modeling sequence, boundary and initial conditions

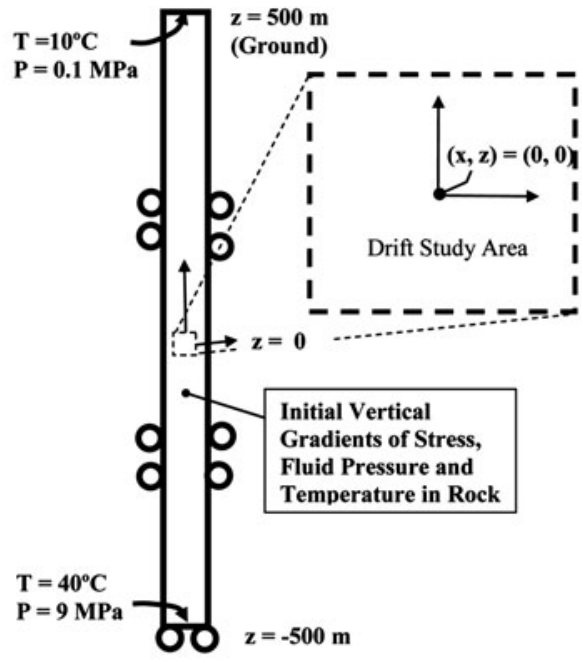

1) Pre-excavation Conditions

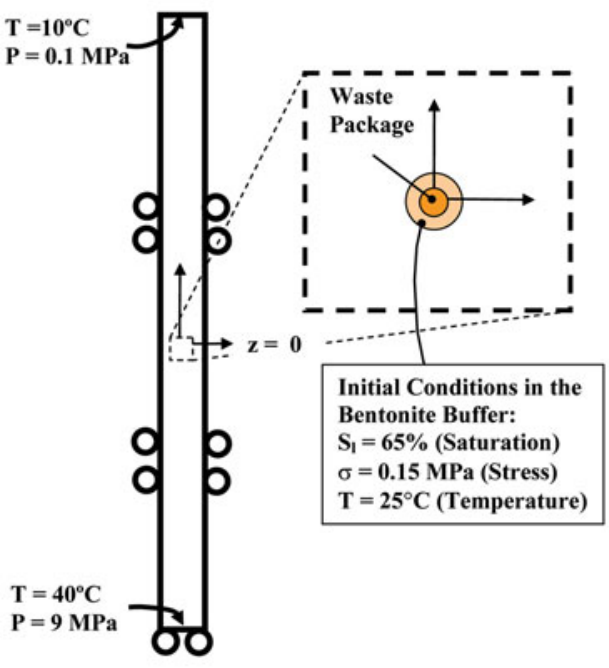

3) Installation of Waste Package and Bentonite Buffer

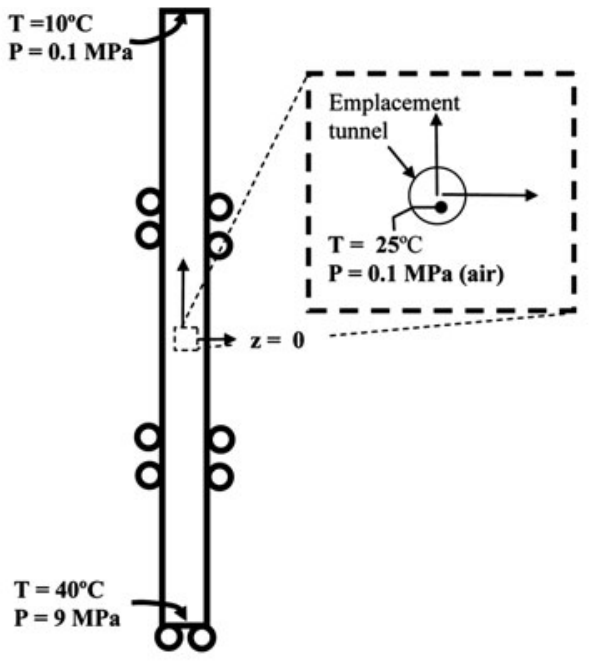

2) Steady State Simulation of Excavation

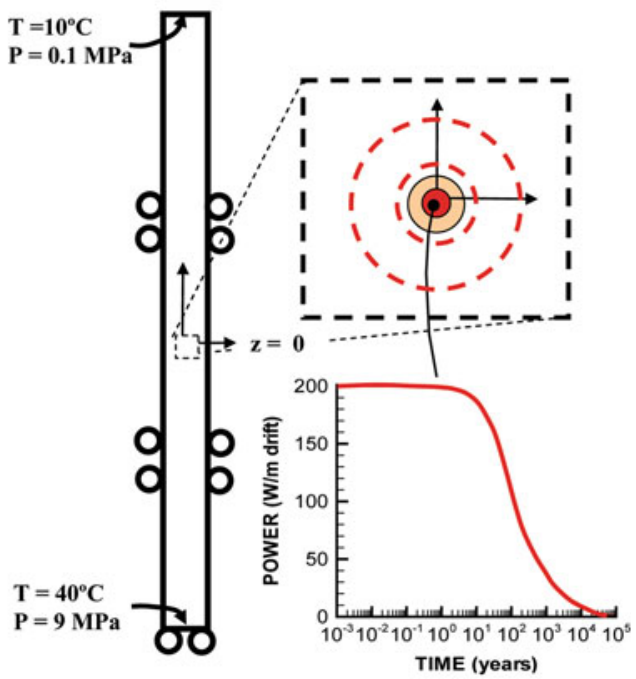

4) Transient Simulation of Post-closure THM 
waste canister and bentonite buffer were installed instantaneously (at a designed initial saturation) and the postclosure simulation begun (Fig. 4c, d). The bentonite buffer was installed with the liquid saturation set to $65 \%$, whereas the gas pressure is kept at $0.1 \mathrm{MPa}$.

\section{Base-Case THM Simulation Results}

Figure 5 presents the calculated evolution of temperature, saturation, fluid pressure, and stress within the buffer. Time $=0$ is at the assumed instantaneous emplacement of waste package and bentonite buffer. As stated in the Sect. 3, at time $=0$, the liquid saturation in the buffer is
$65 \%$ and the gas pressure is $0.1 \mathrm{MPa}$, whereas the temperature is $25{ }^{\circ} \mathrm{C}$. The canister surface temperature peaks at about $91{ }^{\circ} \mathrm{C}$ after 50 years, whereas the peak temperature at the buffer and rock interface is about $77^{\circ} \mathrm{C}$ (Fig. 5a). The resaturation of the buffer is delayed as a result of the low rock permeability, and as a result of high capillarity in the rock, only a slight desaturation of the rock can be observed (Fig. 5b). However, in this case the desaturation of the rock was quite limited, because a rock porosity as high as $15 \%$ along with available mobility provides plenty of nearby water for the resaturation of the buffer. As a result, the time to full resaturation of the buffer is 25 years, precedes the thermal peak. The fluid pressure increases with temperature and peaks at $8.0 \mathrm{MPa}$,
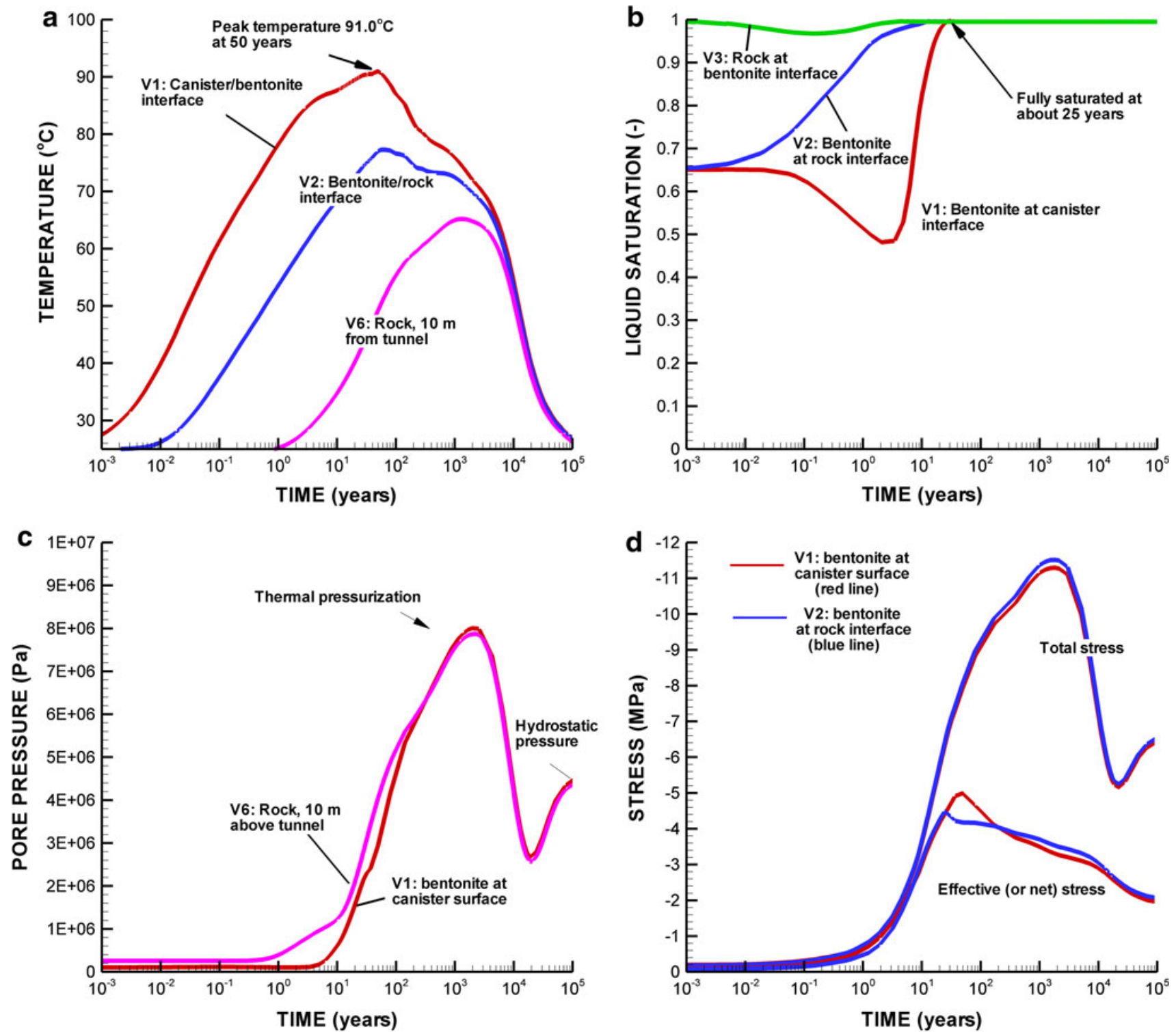

Fig. 5 Simulated evolution of THM processes in the buffer: a Temperature, b liquid saturation, $\mathbf{c}$ fluid pressure, and $\mathbf{d}$ total and effective (or net) stress in the radial direction. See Fig. 2 for locations of $V 1, V 2, V 3$, and $V 6$ 
significantly above the estimated $4.5 \mathrm{MPa}$ hydrostatic pressure (Fig. 5c). This excess fluid pressure above hydrostatic is a so-called thermal pressurization, caused by thermal expansion of the pore fluid that cannot escape in the relatively low-permeability host rock. The excess pressure is initially dissipated through radial and vertical outflow and inflow of water, which lasts for up to 10,000 years until hydrostatic equilibrium pressure is finally attained after about 100,000 years. The temporary pressure decrease to a level below hydrostatic at about 20,000 years is caused by thermal depressurization as a result of declining temperatures. The magnitude and duration of this excess pressure pulse depends on parameters such as rock permeability, and compressibility of water and rock, as will be presented in a parameter study below.

Figure 5d presents the evolution of total and effective stress in the vertical direction in points V1 and V2 within the buffer, i.e., equivalent to the radial stress at both points. The effective stress is actually the net stress (total stress less gas pressure) until the material is fully saturated when it transitions to Terzhaghi effective stress (total stress less liquid pressure). The evolution of total stress in Fig. 5d results from three components: (1) swelling stress caused by saturation changes; (2) poro-elastic stress from fluid pressure changes under saturated conditions; and (3) thermal stress. The stress evolution is relatively uniform within the buffer; the stress evolution near the canister (point V1) follows the stress evolution near the rock wall (point V2). The total stresses at V1 and V2 increase and peak in magnitude at about $-11.5 \mathrm{MPa}$, but then decrease in magnitude to about $-6.5 \mathrm{MPa}$ towards the end of the simulation. The effective stress peaks after about 20-50 years at about -4.5 to $-5 \mathrm{MPa}$ much earlier than the total stress (Fig. 5d). During the early time, the stress in the buffer increase is mainly a result of swelling stress that occurs as a result of reduced suction during saturation of the buffer and is governed by the BBM. For the parameters used to replicate swelling stress experiment on FEBEX bentonite, the swelling stress amounts to about $5 \mathrm{MPa}$ (Rutqvist et al. 2011). In addition, thermal compressive stress is induced within the buffer along with the temperature increase, and after the buffer is fully saturated, poroelastic stress with increasing liquid fluid pressure causes substantial stress increase. In fact, the stress evolution is strongly affected by the thermally induced pressure evolution; thus, we observe strong interaction between the host rock coupled processes and the buffer THM evolution.

Figure 6 presents the mechanical evolution of the buffer in more detail, including stress, stiffness, and porosity. The relatively strong reduction in stress towards 100,000 years in Fig. 6a results from cooling shrinkage at the time when the buffer has become relatively stiff. Indeed, Fig. 6a also
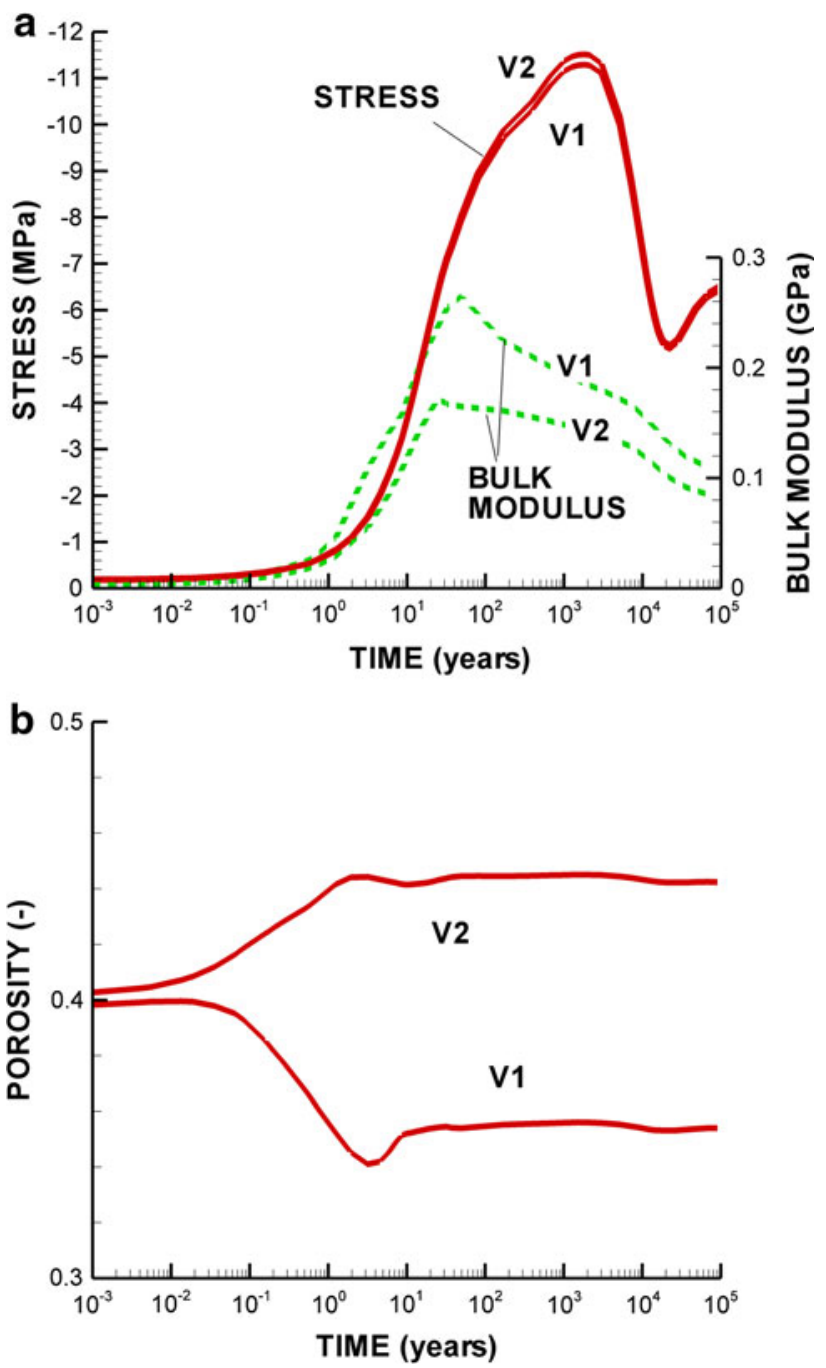

Fig. 6 Simulated evolution of THM processes in the buffer when using the BBM: a tangential stress and bulk modulus, and $\mathbf{b}$ porosity for point $V 1$ and $V 2$ located within the buffer

shows that the bulk modulus increases with stress and is affected by suction changes. The initial bulk modulus is about $2 \mathrm{MPa}$ and peaks at about 200-300 MPa (0.2-0.3 $\mathrm{GPa}$ ), i.e., more than a 100 -fold increase in stiffness. The correlation between bulk modulus and net stress (under unsaturated conditions) or effective stress (under saturated conditions) can be observed when comparing bulk modulus in Fig. 6a with net or effective stress in Fig. 5d.

Figure $6 \mathrm{~b}$ shows the evolution of porosity. A slightly nonuniform porosity evolution can be observed with decreasing porosity at the canister (point V1) and increasing porosity at the rock wall (point V2). The porosity decreases near the canister as a result of drying and suction, which tends to contract the buffer. Meanwhile, the porosity increases near the buffer-rock interface as a result of wetting, which tends to expand the buffer. Interestingly, the porosity change occurring during the first few 
years never recovers even after full saturation and restoration of fluid pressure. The porosity does not recover because the buffer becomes stiff with the stress increases occurring after the first few years. The nonuniform porosity also corresponds to a nonuniform buffer density. The final porosity of about 0.35 at the inner parts of the buffer (V1) corresponds to a dry density of $1.72 \mathrm{~kg} / \mathrm{m}^{3}$, whereas the final porosity of about 0.44 at the outer part of the buffer (V2) corresponds to a dry density of $1.48 \mathrm{~kg} / \mathrm{m}^{3}$. Note that no plastic strain occurred, and hence, the nonuniformity occurred as a result of thermo-hydro-elastic responses in the buffer governed by the BBM.

Figure 7 presents the evolution of total and effective stresses near the tunnel wall (V3 in Fig. 7a) and 10 m away from the tunnel (V6 in Fig. 7b). The results in Fig. 7 show the profound effect of thermal pressurization on the stress evolution. The marked difference in the behavior of horizontal stresses $\left(\sigma_{\mathrm{x}}\right.$ and $\left.\sigma_{\mathrm{x}}^{\prime}\right)$ versus vertical stresses $\left(\sigma_{\mathrm{z}}\right.$ and $\left.\sigma_{z}^{\prime}\right)$ is a result of the different mechanical confinements in the horizontal and vertical directions. Horizontal stress evolution is strongly affected by the no-displacement lateral boundary conditions, which results in both thermal and poro-elastic (horizontal) stresses building up along with increasing temperature and pore pressure. In the vertical direction, on the other hand, total stresses remain constant (except near the tunnel wall) as a result of the free moving ground surface.

The resulting effective stress path $\left(\sigma_{1}^{\prime}\right.$ versus $\left.\sigma_{3}^{\prime}\right)$ at points V3 and V6 is shown in Fig. 8, as is the yield surface for the rock matrix. Actually, most of the rock failure around the tunnel has already occurred during the excavation, both along bedding planes and in the rock matrix between bedding planes. The stress states moves along the yield surface, causing some additional plastic yield until 1 year has elapsed. After 1 year, the stress state moves away from the yield surface as a result of increasing minimum principal stress $\left(\sigma_{3}^{\prime}\right)$. This minimum principal stress is the radial stress normal to the tunnel wall, which increases as a result of swelling and the associated increase in buffer stress. The stress state then remains within the elastic region over the entire 100,000-year simulation time and no further plastic yield takes place.

Our modeling indicated some failure not just on top of the tunnel, but also around the entire tunnel wall, in both the intact rock matrix and along the horizontal bedding planes. The failure zone along bedding planes extends to about $0.4 \mathrm{~m}$ into the rock at the top and bottom of the tunnel, whereas there is a 0.15 -m-thick zone around the entire periphery of the tunnel with both matrix and bedding plane shear failure (Fig. 9). However, despite an anisotropic failure zone developing as a result of bedding plane orientation, the mechanical response in terms of plastic yield and volumetric strain is uniform around the periphery
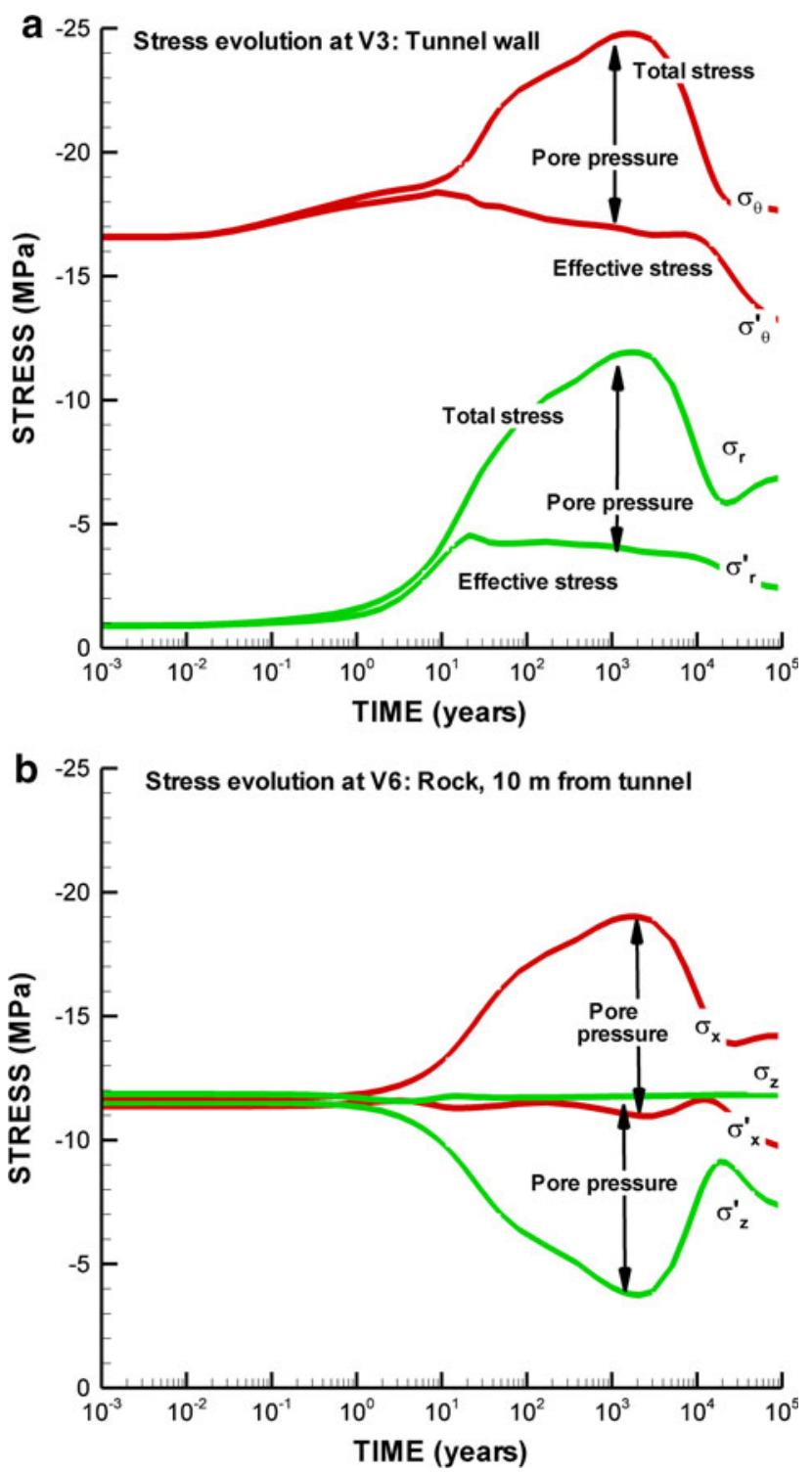

Fig. 7 Calculated evolution of stresses: a stress evolution a point V3 located at the tunnel wall, and $\mathbf{b}$ stress evolution at point V6 located $10 \mathrm{~m}$ away from the tunnel. See Fig. 2 for locations of V3 and V6. The initial stress before excavation is about $-11.7 \mathrm{MPa}$ at $\mathrm{V} 3$ and 11.5 $\mathrm{MPa}$ at $\mathrm{V} 6$

of the tunnel, with a $2 \%$ maximum strain at the tunnel wall. This reflects, first, the fact that the rock can only expand towards the free surface (i.e., the tunnel wall) and second, the fact that the in situ stress was assumed isotropic. Thus, although the zone in which bedding plane shear failure was met extended much more at the top and bottom of the tunnel, these zones were confined and no significant bedding plane slip occurred. Consequently, an excavation damage zone forms as defined in the model simulations as the zone in which more significant plastic strain occurs, in this case $0.15 \mathrm{~m}$ into the rock. 

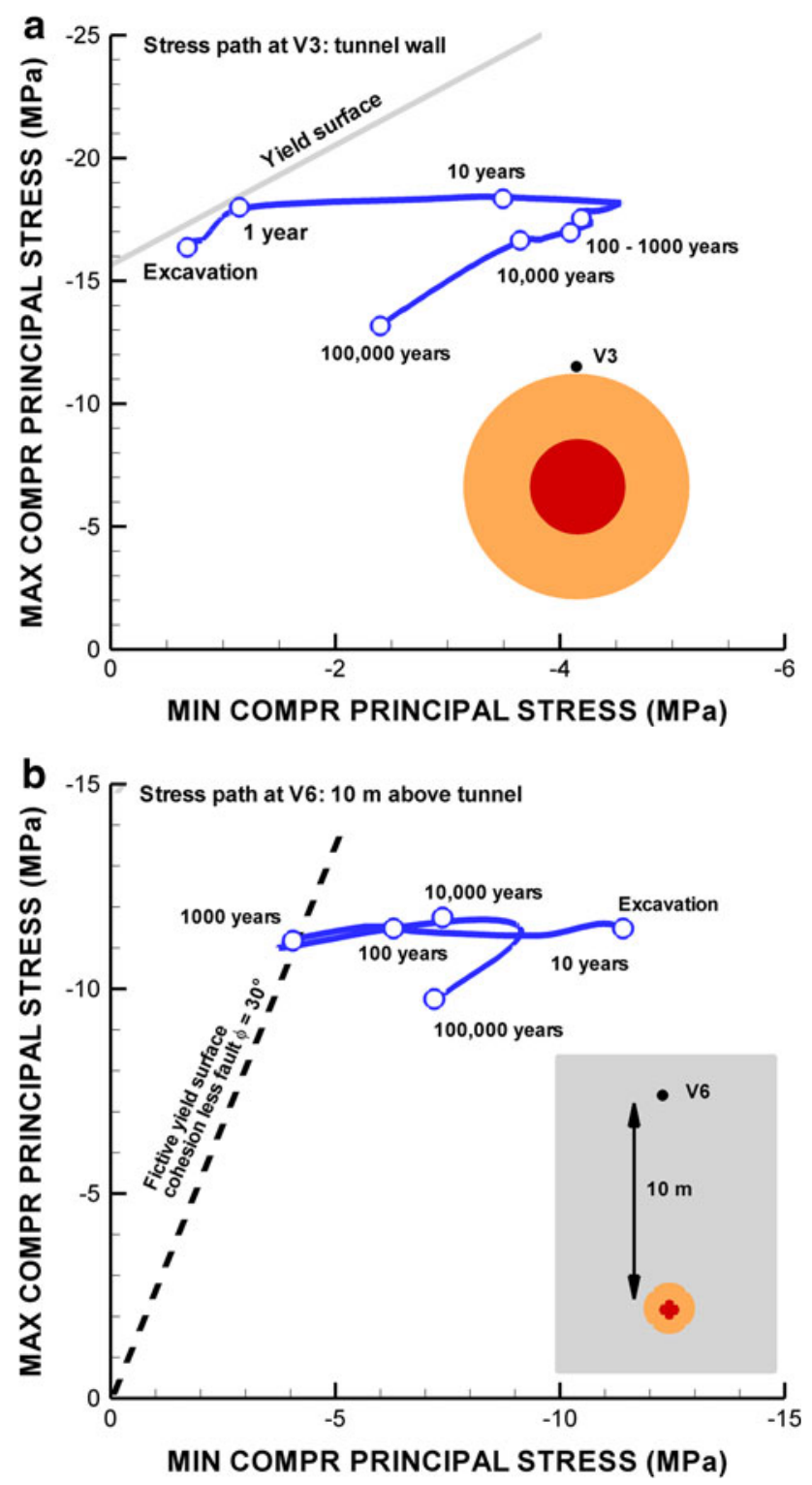

Fig. 8 Calculated principal stress path at a point V3 at the tunnel wall, and $\mathbf{b}$ point $\mathrm{V} 6$ located $10 \mathrm{~m}$ above the emplacement tunnel

Away from the tunnel wall, the stress path in Fig. $8 \mathrm{~b}$ shows that the stress state remains away from any failure in the Opalinus rock at all times. Because the bedding planes are horizontal, no significant shear stress will be induced on these, and there would be no shear failure. The maximum fluid pressure (up to $8 \mathrm{MPa}$ ) is also lower than the minimum principal stress, which is vertical and about $11 \mathrm{MPa}$. The only concern might be if there are pre-existing faults or fractures that would be optimally oriented for shear failure somewhere in the model domain. For example, included in Fig. $8 \mathrm{~b}$ is a dashed line representing the potential failure criterion for fault reactivation in shear having a pre-existing fault of zero cohesion and a $30^{\circ}$ friction angle. The figure shows that the highest potential for such a fault

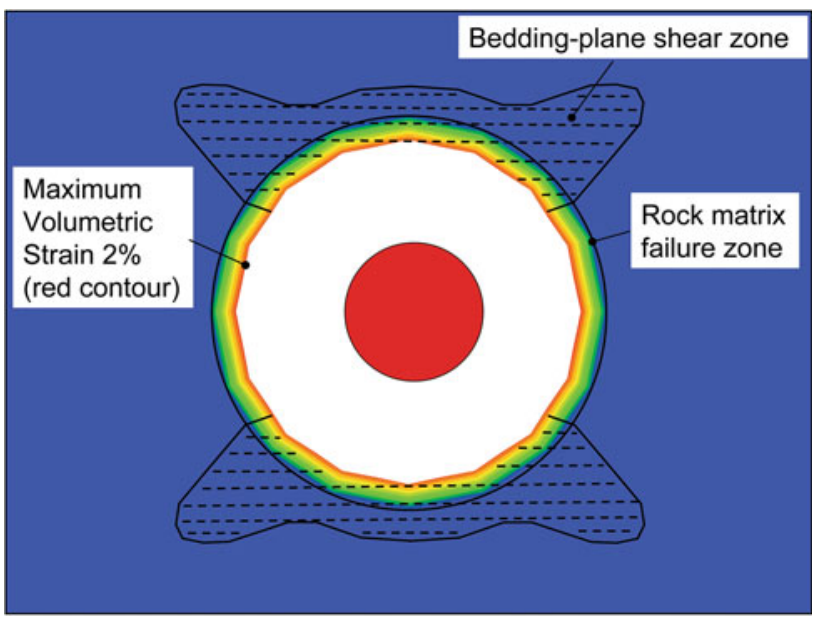

Fig. 9 Volumetric strain contour and extent of failure zones related to horizontal bedding planes and rock matrix

reactivation would be from 100 to 1,000 years, when the differential stress and thermal pressurization in the rock are the highest. This is an issue that should be considered when investigating a site for hosting a repository in a clay formation.

\section{Thermal Management Study and Peak Temperature}

The maximum temperature and temperature-time behavior of the canisters are determined principally by the canister and areal thermal loading-which are controllable parameters-and the ambient temperature and thermal properties of the bentonite backfill and rock. There are no strict criteria for establishing a maximum near-field temperature, but it is generally considered that the concerns regarding assurance of good long-term performance of the bentonite buffer, rather than those associated with corrosion performance of the canister, are the most stringent (NAGRA 2002). Specifically, the canister surface should be maintained at a sufficiently low temperature such that the desirable plasticity, as well as hydraulic and diffusion properties of the buffer material are preserved (NAGRA 2002). The most important potential degradation processes involve cementation as a result of silica dissolution and precipitation, and precipitation of sparingly soluble mineral such as calcite and anhydrite at or near the canister surface. Several studies have proposed a design with a maximum canister surface temperature of $100{ }^{\circ} \mathrm{C}$, because of concerns about bentonite integrity at temperatures above $100{ }^{\circ} \mathrm{C}$ and because of a lack of confidence in the coupled THM models describing the evolution of near-field conditions over the first few hundred years after emplacement (NAGRA 2002). 
In the Swiss concept for a repository in Opalinus clay, the maximum surface temperature for the canister is expected to be well above $100{ }^{\circ} \mathrm{C}$, i.e., higher temperature than in our base-case model simulation. In fact, some of the earlier thermal calculations show that canister temperature could go as high as $160{ }^{\circ} \mathrm{C}$ (NAGRA 2002). The high peak temperature is related to (1) emplacement of the bentonite buffer using granular bentonite with very low water content and low thermal conductivity; (2) a relatively high initial temperature at desired emplacement depth in Opalinus clay; and (3) the relatively low thermal conductivity of Opalinus clay.

There are very few data available for thermal effects on bentonite (Delage et al. 2010). However, laboratory experiments have shown that at a temperature of $150{ }^{\circ} \mathrm{C}$, for granular bentonite with an initial dry density of $1,500 \mathrm{~kg} / \mathrm{m}^{3}$, a $\sim 50 \%$ drop in swelling pressure occurs due to cementation, whereas at $125^{\circ} \mathrm{C}$, only minor reduction in swelling is observed (NAGRA 2002). As a result, the thermal constraint for the bentonite specified in NAGRA (2002) for the design for emplacement tunnels in Opalinus clay was that the outer half of the bentonite should remain below $\sim 125{ }^{\circ} \mathrm{C}$, so as to retain maximum swelling capacity in at least this region to ensure a good quality hydraulic seal around each canister. Current in situ experiments at Mont Terri are being conducted at temperatures well over $100{ }^{\circ} \mathrm{C}$, including the ongoing $\mathrm{HE}$ heater test in which the maximum temperature is set to $140{ }^{\circ} \mathrm{C}$. Such experiments will be important for investigating thermal effects on bentonite and clay host rock under in situ conditions.

In the base-case simulation, we designed the repository in such a way that the peak temperature would be less than $100{ }^{\circ} \mathrm{C}$. To achieve this, we assumed a waste deposition after 60 years of interim storage (initial heat power per $1,818 \mathrm{~W}$ per waste package), deposition at $500 \mathrm{~m}$ (initial temperature $25^{\circ} \mathrm{C}$ ), a 50-m tunnel spacing, canisters emplaced every 8th meter along the emplacement tunnels, and a bentonite buffer consisting of pre-compacted bentonite blocks (as in the FEBEX experiment), having an initial saturation of $65 \%$. We found in our sensitivity study that the initial saturation in the buffer could be an important factor for the peak temperature, as in the NAGRA (2002) model simulations. The results indicate that a change in initial saturation affects the temperature during the first 10 years, before any significant wetting of the buffer from the surrounding rock.

Figure 10 presents one simulation example in which the effect of initial buffer saturation is investigated. In this simulation case, we also reduce the space between canisters from 4 to $3 \mathrm{~m}$ (i.e., a 4 -m-long canister every $7 \mathrm{~m}$ ), leading to a higher line load along the tunnel. With such a heat load and for an extreme case of $1 \%$ initial saturation, the
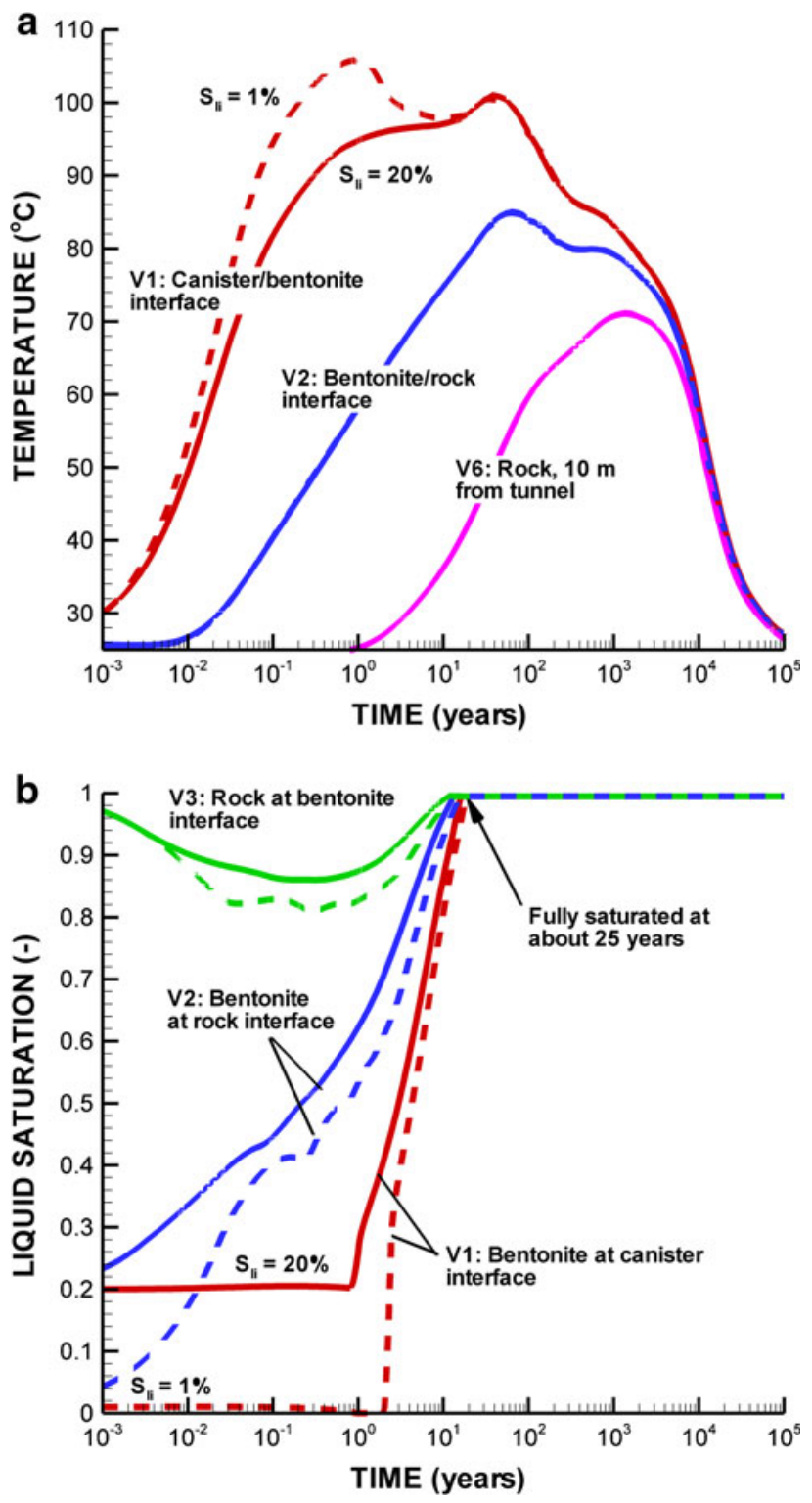

Fig. 10 Evolution of a temperature and $\mathbf{b}$ liquid saturation for two cases of buffer initial saturation $\left(S_{\mathrm{li}}=1\right.$ and $\left.20 \%\right)$ representing conditions for a buffer emplacement using granular bentonite

maximum temperature at first peak already after 1 year is about $106{ }^{\circ} \mathrm{C}$, whereas a second peak temperature of about $100{ }^{\circ} \mathrm{C}$ occurs after about 50 years (Fig. 10a). However, based on observations at the Mont Terri field experiments, the assumption of a $1 \%$ initial saturation for the buffer in these simulations appears unrealistic. In fact, when emplacing the granular bentonite, the bentonite grains quickly adsorb moisture from the air and equilibrate with the relative humidity in the air, then swell to tighten voids between the bentonite grains, forming a more homogenous buffer with saturation of $20-25 \%$. If the initial saturation is $20 \%$, Fig. 10a shows that the maximum temperature does not occur until the second peak, after 50 years, and remains at $100{ }^{\circ} \mathrm{C}$. 


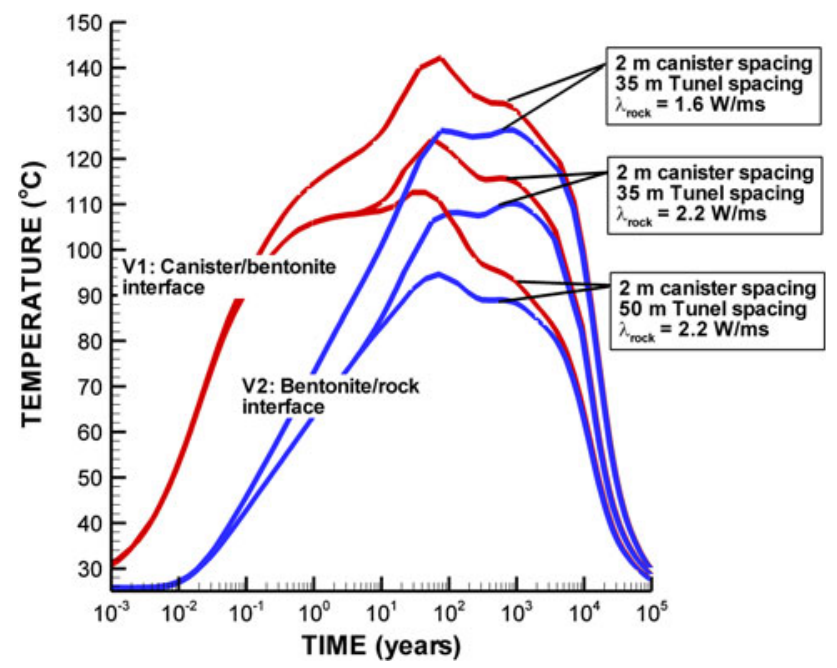

Fig. 11 Sensitivity of temperature to changes in canister spacing, tunnel spacing and rock thermal conductivity in the case of $20 \%$ initial buffer saturation

With an initial buffer saturation of $20 \%$ or higher, the peak temperature depends on tunnel and canister spacing, as well as the thermal conductivity of the host rock (Fig. 11). A change in canister spacing will affect the thermal line load along the axis of the emplacement tunnels. When we reduce the space between the canisters to $1 \mathrm{~m}$ (i.e., a canister every $6 \mathrm{~m}$ ), the canister peak temperature increases to $113{ }^{\circ} \mathrm{C}$ at 40 years, whereas the temperature at the rock-buffer interface peaks at $95{ }^{\circ} \mathrm{C}$. When we reduce the distance between emplacement tunnels to $35 \mathrm{~m}$ (and keeping $1 \mathrm{~m}$ canister spacing), the canister temperature peaks at about $125^{\circ} \mathrm{C}$ at 60 years, while the temperature at the rock-buffer interface peaks at $110{ }^{\circ} \mathrm{C}$ after 800 years. If in addition we decrease the thermal conductivity from 2.2 to $1.6 \mathrm{~W} / \mathrm{mK}$, temperatures up to $142{ }^{\circ} \mathrm{C}$ are reached and the entire buffer would be above $125^{\circ} \mathrm{C}$ for thousands of years. Note that the thermal conductivity of $2.2 \mathrm{~W} / \mathrm{mK}$ corresponds to the average value based on anisotropic thermal conductivity back-calculated from field experiments at Mont Terri (Gens et al. 2007), whereas a value of $1.6 \mathrm{~W} / \mathrm{mK}$ would correspond to the vertical thermal conductivity, perpendicular to the bedding planes of Opalinus clay.

\section{Buffer Resaturation Time}

The bentonite buffer will resaturate and swell with inflow from the surrounding rock mass. A certain swelling pressure is generally expected to assure buffer homogeneity and tightness against the surrounding rock wall. Time to full resaturation and swelling depends on a number of parameters, most importantly the hydraulic properties of the rock and the bentonite. We found in our previous simulation that the resaturation time is about 24 years, even for a low Opalinus clay permeability of $5 \times 10^{-20} \mathrm{~m}^{2}$ (Fig. 10b). The 24-year resaturation time does not change significantly with the different options of heat load or initial saturation of the buffer. The 24-year resaturation is well before thermal peak and peak thermal stress meaning that swelling pressure was fully developed to provide additional support to the tunnel wall and thereby prevented further damage to the EDZ.

We conducted a parameter study in which we varied the rock permeability and noted the time to reach $99 \%$ saturation at the canister surface. Figure 12 shows that for the base case, the time to $99 \%$ saturation is 24 years. If the permeability is one order of magnitude lower (i.e., $k=5 \times 10^{-21} \mathrm{~m}^{2}$ ), the resaturation time increases to 55 years. Increasing rock permeability by one order of magnitude results in a decrease in resaturation time to 20 years. Figure 12 also shows that if rock permeability were higher than about $1 \times 10^{-16} \mathrm{~m}^{2}$, the resaturation time is 16.3 years and independent of the rock-mass permeability. Other parameters that affect the resaturation time to a lesser degree are rock porosity and compressibility, as well as water retention and relative permeability functions. For example, reducing the capillary strength for the Opalinus clay by an order of magnitude (i.e., reducing van Genuchten constant $\mathrm{P}_{0}$ from $48 \mathrm{MPa}$ to $4.8 \mathrm{MPa}$ ) resulted in a slightly delayed resaturation of the buffer. Buffer resaturation was delayed because of more substantial desaturation of the Opalinus rock surrounding the emplacement tunnel. This desaturation results from high suction in the bentonite at its initial saturation of $65 \%$. A

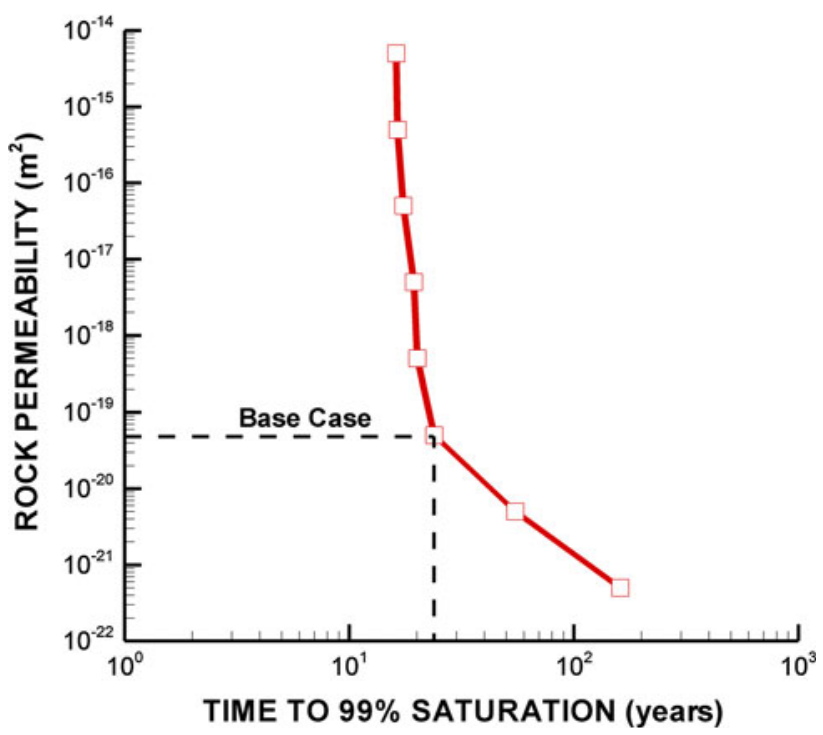

Fig. 12 Calculated time to full saturation (taken as the time to $99 \%$ saturation) as a function of rock permeability. Base-case simulation with a permeability of $5 \times 10^{-20} \mathrm{~m}^{2}$ resulted in a 24 year resaturation time 
change in the relative permeability function of the host rock had only a minor impact on the resaturation time. The minor impact of the relative permeability function is not surprising considering that only a slight desaturation of the rock mass occurred; a result of the shape of the water retention curve. Initially, the rock is fully saturated, while the buffer is $65 \%$ saturated at high suction. A strong pressure gradient from the host rock to the bentonite results in fluid flow from the host rock to the buffer. This results in desaturation of the host rock (see point V3 in Fig. 5). In the case of lower $\mathrm{P}_{0}$ for the host rock, the saturation is lower for a given suction.

\section{Thermal Pressurization}

Our base-case analysis showed a significant thermal pressurization, with a pressure peak at 8.0 MPa and the excess pressure lasting for up to 10,000 years. Such thermal pressurization has been observed at Mont Terri heater experiments, such as the HE-D heater test (Gens et al. 2007). According to Gens et al. (2007), the magnitude of thermal pressurization depends on the compressibility and thermal expansion properties of the fluid, solid grains, and skeleton. In this study, we simulated the thermal pressurization through the TOUGH2 fluid-flow simulation, assigning pore compressibility defined as pore compressibility $c_{p}\left(\mathrm{~Pa}^{-1}\right)$, defined as $(1 / \phi)(\partial \phi / \partial \mathrm{P})_{\mathrm{T}}$ and a pore (thermal) expansivity $c_{T}\left(\mathrm{~T}^{-1}\right)$ defined as $(1 / \phi)(\partial \phi / \partial \mathrm{T})_{\mathrm{p}}$. We estimated the pore compressibility in the TOUGH2 simulation for uniaxial strain conditions, because the model is constrained laterally, but is free to move vertically as a result of the free moving boundary at the ground surface. Under these conditions, the pore compressibility can be determined approximately from Settari et al. (2005):

$c_{p} \cong \frac{1}{K \varphi_{0}}\left(1-\frac{2(1-2 v)}{3(1-v)}\right)$

where $K$ is the bulk modulus and $v$ is the Poisson's ratio. Using parameters for the Opalinus clay listed in Table 3, we arrive at a pore compressibility of $1 \times 10^{-9} \mathrm{~Pa}^{-1}$.

For the pore thermal expansivity $c_{T}$, the approximation is less clear. For example, Gens et al. (2007) considered both the grain thermal expansivity and the skeleton thermal expansivity in their modeling of the Mont Terri HE-D heater experiment in Opalinus clay. Grain thermal expansion would tend to invade open pores, leading to a reduction in porosity with temperature, while thermal expansion of the skeleton would tend to increase the porosity. Gens et al. (2007) argued the value of grain and skeleton thermal expansion would be equal in the case of heating the Opalinus clay, because no significant structural rearrangement is expected during limited thermal expansion. In such a case, using a reservoir simulator such as TOUGH2, this would be approximated by setting $c_{T}=0$, because the effect on porosity caused by thermal expansion of the skeleton would be completely offset by grain thermalexpansion effects. This results in a negligible rock-thermalexpansivity effect on thermal pressurization. In Gens et al. (2007), an average linear thermal expansivity of $1.4 \times 10^{-5}{ }^{\circ} \mathrm{C}^{-1}$ was assigned for Opalinus clay, corresponding to a volumetric thermal expansivity of about $4.2 \times 10^{-5}{ }^{\circ} \mathrm{C}^{-1}$. The volumetric thermal expansion coefficient of water is temperature dependent; for heating from 25 to $70{ }^{\circ} \mathrm{C}$, an average thermal expansion of $4.3 \times 10^{-4}{ }^{\circ} \mathrm{C}^{-1}$ would apply. This indicates that the thermal expansion of the Opalinus clay could be on the order of $10 \%$ of the thermal expansion of water, thus might have a relatively small impact on the thermal pressurization.

A sensitivity study showed that the assigned rock-mass permeability has a significant impact on thermal pressurization. For example, if the rock were completely impermeable, the thermal pressurization could be estimated as

$\Delta P=\frac{\Delta T c_{T w}}{\left(c_{w} \varphi+c_{p}\right)}$

where $c_{T w}$ is volumetric thermal expansion of water, and $c_{w}$ and $c_{p}$ are (respectively) water and pore compressibility. For a temperature increase from 25 to $70{ }^{\circ} \mathrm{C}$, $c_{T w}=4.3 \times 10^{-4}{ }^{\circ} \mathrm{C}^{-1}, \quad c_{w}=4.4 \times 10^{-10} \mathrm{~Pa}^{-1}$ and $c_{p}=1.0 \times 10^{-9}{ }^{\circ} \mathrm{C}^{-1}$, Eq. (27) results in a pressure change of $18 \mathrm{MPa}$. However, the permeability of the rock, although quite small, causes outflow from the pressurized rock that effectively prevents such high pressure change.

Figure 13 presents results for a rock permeability reduced to $1 \times 10^{-20} \mathrm{~m}^{2}$, five times lower than in the base case, but still within the range of Opalinus clay (Gens et al. 2007). Reducing the permeability by a factor of 5, while keeping all other parameters as in the base case, the peak pressure increases from 8 to $9 \mathrm{MPa}$. In the extreme case of both low permeability and a compressibility reduced by a factor of 2 , the pressure peaks at $13 \mathrm{MPa}$. Such a high pressure would in practice be unsustainable, because the lithostatic stress (from the weight of the overburden rock) is just above $11 \mathrm{MPa}$. As shown in Fig. 7b, the simulations show that the total vertical stress is indeed constant and just above $11 \mathrm{MPa}$ as a result of the free vertical expansion of the rock, which in turn is a result of the free moving ground surface boundary. A thermal pressurization up to $13 \mathrm{MPa}$ would result in vertical tensile effective stress that could cause fracturing and part the horizontal bedding planes In our base-case model simulations we assumed that the rock has a homogenous and low permeability over the entire model domain. In Fig. 13, we also show one case in which we have an Opalinus clay $150 \mathrm{~m}$ thick (75 $\mathrm{m}$ above and 75 


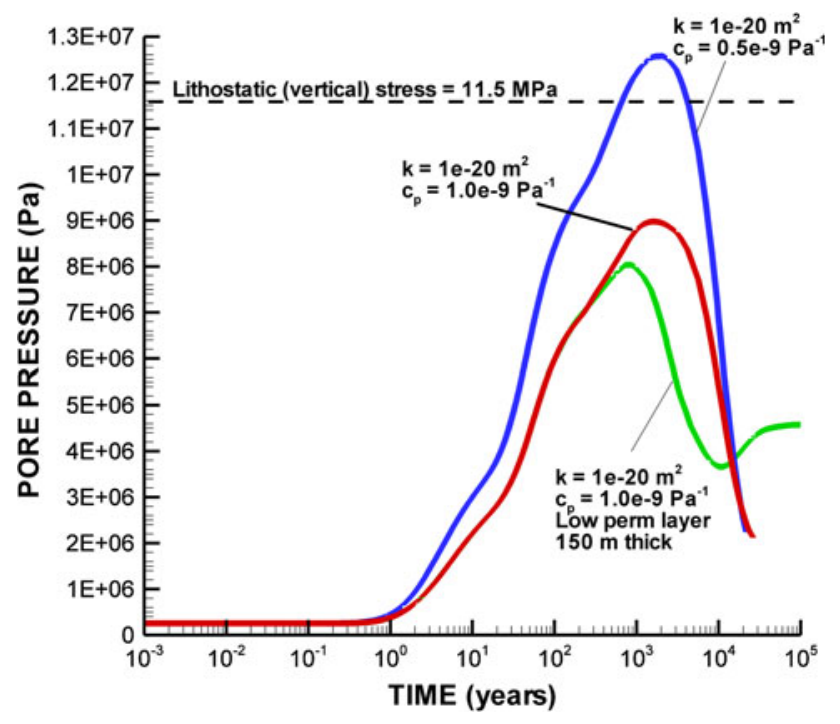

Fig. 13 Sensitivity analysis related to thermal pressurization in the low-permeability Opalinus clay

below repository depth), with layers above and below having 2 orders of magnitude higher permeability. In such a case the thermal pressurization is still substantial, but pressure drops faster, since fluids can flow from the pressurized volume towards the more permeable formations. The magnitude of thermal pressurization might also be reduced as a result of pressure diffusion within a more permeable excavation disturbed zone around emplacement tunnels; a feature that was not considered in this analysis. However, the simulation results clearly show that thermal pressurization can have a significant impact on a nuclear waste repository in low-permeability clay and needs to be carefully analyzed for site-specific conditions.

\section{Modeling THMC Processes Using Elastic CM Coupling}

As mentioned, the reactive transport simulator TOUGHREACT was linked with FLAC3D, providing a necessary framework for coupled THMC modeling. The calculation procedure of TOUHGREACT-FLAC3D is given Fig. 14, which is very similar to that of TOUGH-FLAC, except that chemistry is added to the flowchart. The central THMC model is where THC and mechanical data are exchanged. TOUGHREACT feeds the state variable such as temperature, pressure and ion concentration into the THMC model which calculates the pressure change, strains caused by temperature, saturation and ion concentration changes. And then FLAC updates the effective stress and strain and feed back to THMC model for calculating the porosity changes which will be used by TOGHREACT to update relevant hydraulic properties such as permeability. As we can see,

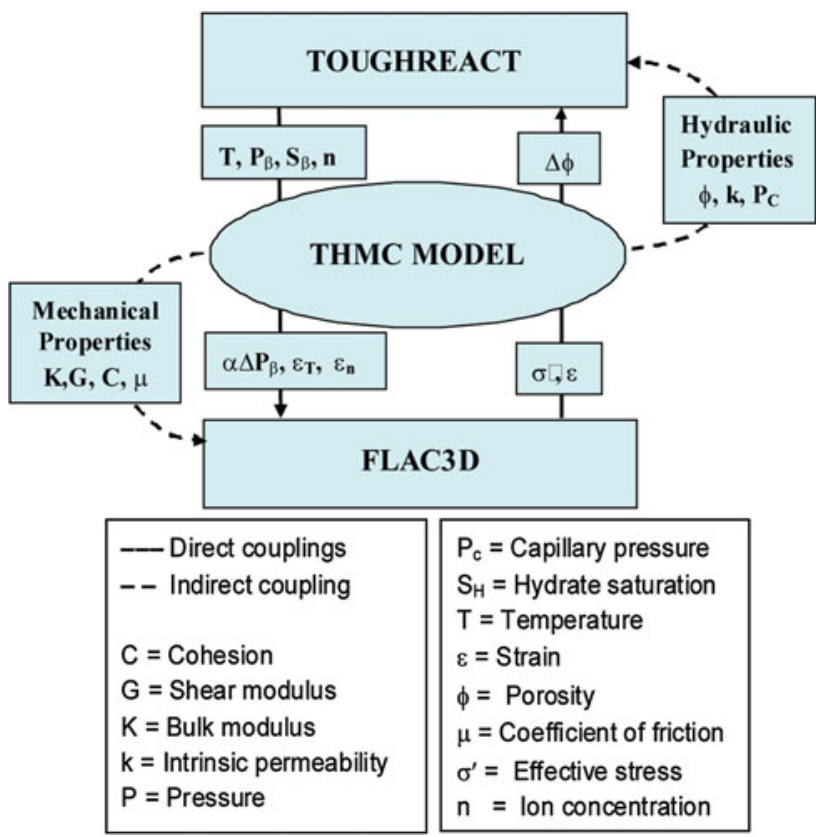

Fig. 14 The calculation procedure of TOUGHREACT-FLAC3D

the core of this procedure is the coupling relations implemented in the central THMC model block. In this section, we present a simple approach for linking chemistry to mechanical analysis related to the chemical evolution and swelling of a bentonite buffer. While incorporation of more advanced approaches for handling this coupling into TOUGHREACT-FLAC3D is under consideration, this study employs the relatively simple approach of (Laredj et al. 2010).

Laredj et al. (2010) extended the nonlinear elastic model for mechanical deformation (Thomas and He 1995) by adding a chemical concentration term. It is assumed that the increment of total strain is the sum of the strain increments due to the changes in net mean stress, suction, and chemical solute concentration:

$d \varepsilon=d \varepsilon_{p}+d \varepsilon_{s}+d \varepsilon_{n}$

where the subscripts $p, s$, and $n$ refer to net mean stress, suction and chemical solute concentrations, respectively, which can be represented by the ionic strength of the porewater solution. The stress-strain relationship can be expressed as:

$d \sigma=D\left(d \varepsilon-d \varepsilon_{s}-d \varepsilon_{n}\right)=D\left(d \varepsilon-A_{s} d s-A_{n} d n\right)$

with

$d \varepsilon_{s}=A_{s} d s$

$d \varepsilon_{n}=A_{n} d n$

where $D$ is the elastic matrix, $A_{s}$ and $A_{n}$ are constants, and $n$ is the ion concentration of the pore water. Note that $A_{n}$ is 
constant only when the strain is minimal and could also be affected by the initial state of the soil. Karnland et al. (2005) showed that $A_{n}$ would only be constant if the initial density of a swelling clay is high. In practical calculation, $A_{n}$ has to be derived by experimental data which might require $A_{n}$ to be a function of concentration as discussed below.

Laredj et al. (2010) determined these parameters by modeling calibration against swelling experiments performed on Kunigel-V1 bentonite (Ochs et al. 2004), a candidate material for the bentonite buffer in the Japanese nuclear waste program. The strain resulting from chemical solute concentration changes was taken as the difference between the suction-related strain and the experimentally observed strain. Here, we first adopt the linear elastic swelling model of Rutqvist et al. (2011), using a swelling strain that is linearly proportional to the saturation degree:

$d \sigma=3 K \beta_{s w} d s_{l}$

where $K$ is the bulk modulus, $\beta_{s w}$ is a moisture swelling coefficient, and $s_{l}$ is the saturation. To consider the swelling results from both moisture and chemical concentration changes, we add the strain due to chemical concentration change according to:

$d \sigma=3 K \beta_{s w} d s_{l}+A_{n} d n$

Similarly to Laredj et al. (2010), we estimated the parameters for the primary and secondary swelling from laboratory experimental results. We considered laboratory experimental data on FEBEX bentonite presented in Castellanos et al. (2008), calibrating $A_{s}$ (or $\beta_{S W}$ ) and $A_{n}$ against their laboratory data with respect to swelling stress evolution during saturation with deionized water and solutions of different concentrations and compositions (Zheng et al. 2011). First, we noted that for a bentonite sample compacted to a dry density of $1.65 \mathrm{~g} / \mathrm{cm}^{3}$, a swelling pressure of $-4.5 \mathrm{MPa}$ was achieved when wetting the sample with deionized water from an initial saturation of $59 \%$ (14\% water content) to full saturation. For an average bentonite-buffer bulk modulus of $20 \mathrm{MPa}$, we can determine $\beta_{S W}$ from Eq. (32) for $d n=0$ (no concentration change) to $\beta_{S W}=d \sigma /\left(3 K d S_{l}\right)=-4.5 \times 10^{6} /(3 \times 20 \times$ $\left.10^{6} \times 0.41\right)=-0.183$. The minus sign signifies that a positive saturation change (increase in saturation) results in a compressive stress that is negative according to the adopted sign convention.

$A_{n}$ was determined from observations of the data from the same swelling stress experiment saturated with solutions of different concentration (Castellanos et al. 2008). Three saturation solutions were used therein for the oedometer test: distilled water, $0.1 \mathrm{M} \mathrm{NaCl}, 2.5 \mathrm{M} \mathrm{NaCl}$ and $5.5 \mathrm{M} \mathrm{NaCl}$. The FEBEX bentonite of $14 \%$ water content has an ionic strength of $0.25 \mathrm{M}$ according to Fernández

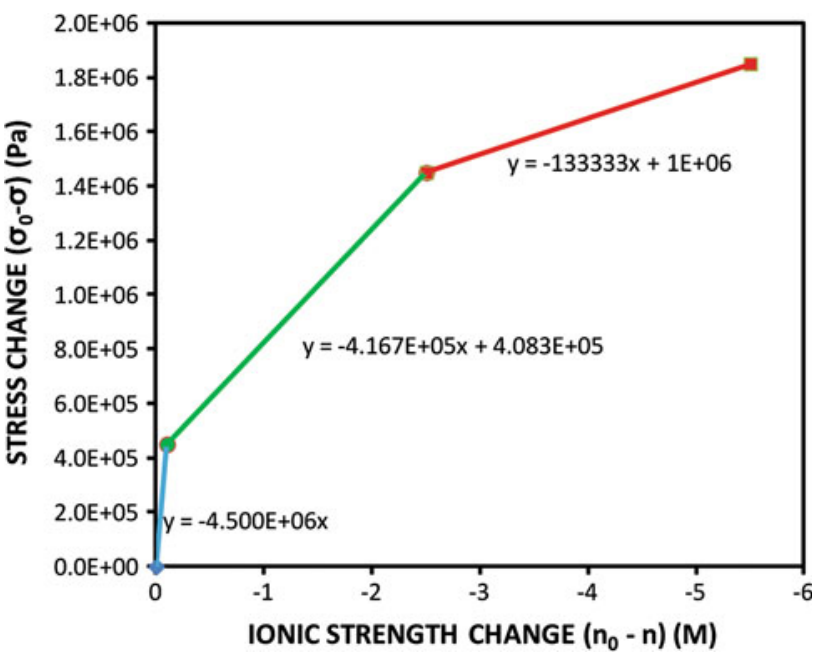

Fig. 15 The measured swelling pressure changes $\left(\sigma_{0}-\sigma\right)$ versus ionic strength change $\left(n_{0}-n\right)$ for bentonite (Castellanos et al. 2008), where $\sigma_{0}$ is the swelling pressure when bentonite is saturated with distilled water of ionic strength, $n_{0}$ (assumed to zero for distilled water), while $\sigma$ is the measured swelling pressure when bentonite is saturated with solution of ionic strength $n$

et al. (2001). If chemical reactions such as mineral dissolution or cation exchange are neglected, then dispersion and mixing are the dominant processes that control the pore water composition in bentonite and eventually the pore water composition in bentonite would be very similar to that in the host clay formation. We therefore assume here that pore water composition is the same as the solution used to saturate the bentonite. By plotting the stress changes as a function of the ionic strength changes in the pore water (see Fig. 15), we can determine $A_{n}$ from the slope of the linear relations curve of $\sigma_{0}-\sigma$ versus $n_{0}-n$ as in Fig. 15. We found that $A_{n}$ is not constant; it decreases as the ion concentration of saturation solution increases. The following expression is derived to accommodate such variation:

$A_{n}=-10^{(-0.364 \ln (n)+5.84)}$

Using these parameters, we then examined the effect of chemically induced swelling on our THM base-case repository simulation. Thus, we conducted a linked TOUGHREACT-FLAC3D analysis over the 100,000-year simulation time for the base-case geometry, heat load, and material properties. For our chemical analysis in TOUGHREACT, the initial water for the bentonite buffer was taken from Fernández et al. (2001); whereas the pore water composition was taken from Fernández et al. (2007), with an ionic strength of $0.43 \mathrm{M}$.

The chemical calculation was simplified-concentration changes are exclusively determined by the mixing caused by diffusion and dispersion without consideration of any reactions. We examined the effect of chemically induced 

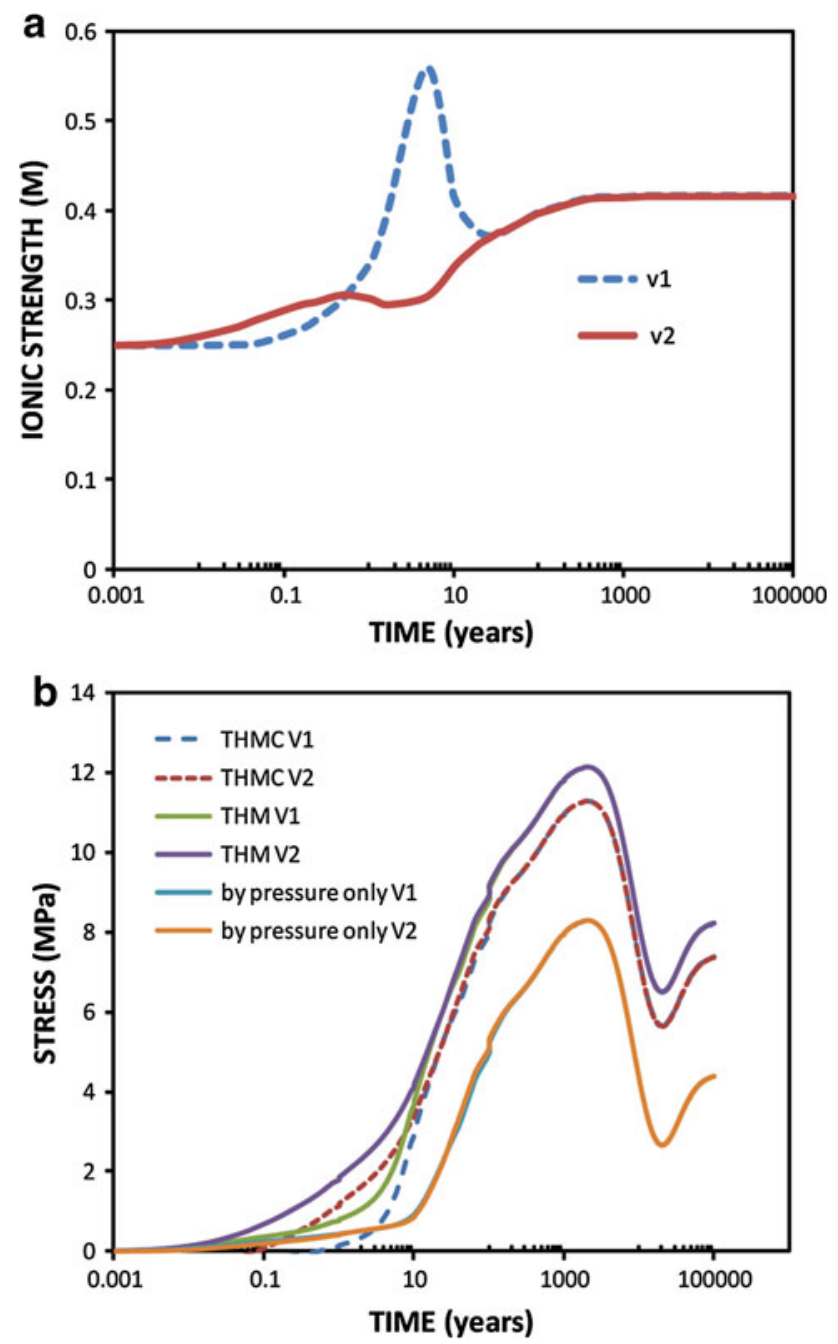

Fig. 16 THMC simulation results related to primary and secondary swelling, in which the secondary swelling is related to chemically induced swelling as function on ionic concentration: time evolution of a ionic strength and $\mathbf{b}$ compressive stress increase caused by (1) fluid pressure, (2) fluid pressure and primary swelling (THM), and (3) fluid and both primary and secondary swelling effects (THMC)

swelling by comparing two cases: the first case corresponding to the linear elastic swelling model represented in Eq. (32), called THM here; the second case corresponding to the elastic swelling model that accounts for both moisture and chemical concentration changes as represented in Eq. (33), called THMC here. Comparing the calculated stress fields for the THM and THMC cases allows us to evaluate the contribution of chemically induced swelling.

Figure 16 presents the ionic strength and the stress evolution at V1 and V2 within the buffer for THM and THMC simulation cases. Figure 16a shows that the ionic concentration within the buffer will (in general) increase with time as the buffer becomes saturated with water from the Opalinus clay. But a peak appears around 2-3 years at V1, because the evaporation caused by the heating leads to a decrease in water saturation (see Fig. 5a) and subsequently an increase in concentration. The peak is the combined effect of dispersion and evaporation. After the bentonite becomes fully saturated, the concentration is largely determined by the dispersion and mixing of two types of waters, which makes the pore water composition in bentonite very similar to that in clay formation. Note that the ionic strength starts to increase even at the canister surface within year, as chemical species are transported by the liquid flow movement towards the dryer inner parts of the buffer (and also by dispersion).

In general, the increase in ionic concentration with time results in a slight loss of swelling pressure (Fig. 16b), about $0.84 \mathrm{MPa}$. At the end of the simulation, we can evaluate the different contributions to the total stress in the buffer, including: (1) swelling stress caused by saturation changes (primary swelling); (2) swelling stress caused by changes in ionic concentration (secondary swelling); and (3) poroelastic stress from fluid pressure changes under saturated conditions. The poro-elastic stress resulting from the restoration of fluid pressure accounts for about $4.5 \mathrm{MPa}$ of total stress, whereas the swelling stress resulting from saturation changes can be calculated from Eq. (32) to account for about 3.8 MPa of total stress. Then, the increase in ionic concentration causes a $0.84 \mathrm{MPa}$ loss of swelling stress, a $22 \%$ reduction. While this simulation serves as a test and demonstration of this approach for modeling THMC processes in the EBS, the exact swelling loss would depend on site-specific geochemical conditions, and would require site-specific analysis.

\section{Concluding Remarks}

This paper presents simulation results related to coupled thermal-hydraulic-mechanical processes in the engineered barrier system (EBS) and clay host rock, in one case considering a possible link to geochemistry. We simulated a generic repository case assuming an EBS design with waste emplacement in horizontal tunnels that are back-filled with bentonite-based swelling clay and with a heat load derived for one type of US reactor spent fuel. We adopted the Barcelona Basic Model (BBM) for modeling of the geomechanical behavior of the bentonite, using properties corresponding to the FEBEX bentonite, and we used clay host rock properties derived from the Opalinus clay stone at Mont Terri, Switzerland. Our THM simulation results show strong THM-driven interactions between the bentonite buffer and the clay host rock. The resaturation of the buffer is delayed as a result of low rock permeability, and the fluid pressure in the host rock is strongly coupled with temperature changes-which, under certain circumstances, could result in a significant increase in pore pressure, leading to an excessive pressure gradient and fluid flow from the 
repository that could last for up to 10,000 years. In our analysis of the peak temperature, we found that the initial saturation of the buffer, which would likely be at least $20 \%$ even in the case of granular bentonite emplacement, provides sufficient thermal conductivity to lower the early time canister temperature. Moreover, using the BBM, the bentonite buffer showed a rather complex geomechanical behavior affected by the thermal pressurization in the surrounding rock. This behavior led to a final state of full swelling that is not as homogenous as expected, but rather has a slightly nonuniform density distribution. Nevertheless, the simulation shows that the swelling of the buffer functions to provide an adequate increase in confining stress on the tunnel wall, leading to a stabilization of any failure that may have occurred during the tunnel excavation.

Finally, we attempted to link THM processes with chemistry, focusing on the evolution of primary and secondary swelling, in which the secondary swelling is caused by chemical changes that in turn were evaluated using a transport simulation model. For a simplified linear swelling model with parameters calibrated against laboratory data, we simulated a slight loss of swelling pressure as a result of buffer saturation with ionized water from the surrounding Opalinus clay. We see this as a first approach and test of THMC modeling of the EBS using TOUGHREACT-FLAC in conservative transport mode, with future work focusing on THMC-coupled modeling through the BBM model extended to double-structure behavior, in which chemistry is linked to mechanics at the micro-structural level. Overall, this study demonstrates that the EBS, near-field, and far-field THMC processes are interactive, meaning that EBS, near-field, and far-field natural system responses cannot be analyzed independently of each other, but instead requires coupled model simulations including all systems, using site-specific conditions and parameters.

Acknowledgments Funding for this work was provided by the Used Fuel Disposition Campaign, Office of Nuclear Energy, of the US Department of Energy under Contract Number DE-AC0205CH11231 with Berkeley Lab. We thank Peter Swift and Carlos Jove-colon at Sandia National Laboratories, and two anonymous reviewers for constructive comments on the initial manuscript. Editorial review by Dan Hawkes of the Lawrence Berkeley National Laboratory is greatly appreciated.

Open Access This article is distributed under the terms of the Creative Commons Attribution License which permits any use, distribution, and reproduction in any medium, provided the original author(s) and the source are credited.

\section{References}

Alonso EE, Gens A, Josa A (1990) A constitutive model for partially saturated soils. Geotechnique 40:405-430
Alonso EE, Alcoverro J, Coste F, Malinsky L, Merrien-Soukatchoff V, Kadiri I, Nowak T, Shao H, Nguyen TS, Selvadurai APS, Armand G, Sobolik SR, Itamura M, Stone CM, Webb SW, Rejeb A, Tijani M, Maouche Z, Kobayashi A, Kurikami H, Ito A, Sugita Y, Chijimatsu M, Börgesson L, Hernelind J, Rutqvist J, Tsang C, Jussila P (2005) The FEBEX benchmark test: case definition and comparison of modelling approaches. Int J Rock Mech Min Sci 42:611-638

Barnichon J, Volckaert G (2003) Observations and predictions of hydromechanical coupling effects in the Boom clay, Mol Underground Research Laboratory, Belgium. Hydrogeol J 11:193-202

Castellanos E, Villar MV, Romero E, Lloret A, Gens A (2008) Chemical impact on the hydro-mechanical behaviour of highdensity FEBEX bentonite., Phys Chem Earth Parts A/B/C 33(Supplement 1):S516-S526

Corkum AG, Martin CD (2007) The mechanical behaviour of weak mudstone (Opalinus clay) at low stresses. Int J Rock Mech Min Sci 44:196-209

Delage P, Cui YJ, Tang AM (2010) Clays in radioactive waste disposal. J Rock Mech Geotech Eng 2:111-123

Fernández A, Cuevas J, Rivas P (2001) Pore water chemistry of the FEBEX bentonite. Mat Res Soc Symp Proc 663:573-588

Fernández AM, Turrero MJ, Sánchez DM, Yllera A, Melón AM, Sánchez M, Peña J, Garralón A, Rivas P, Bossart P, Hernán P (2007) On site measurements of the redox and carbonate system parameters in the low-permeability Opalinus clay formation at the Mont Terri Rock Laboratory. Phys Chemi Earth Parts A/B/C 32(1-7):181-195

Fouché O, Wright H, Le Cléac'h J, Pellenard P (2004) Fabric control on strain and rupture of heterogeneous shale samples by using a non-conventional mechanical test. Appl Clay Sci 26:367-387

Gens A (1995) Constitutive Laws. In: Gens A, Jouanna P, Schrefler BA (eds) Modern issues in non-saturated soils. Springer, Wien, pp 129-158

Gens A, Sheng M, Sánchez D (2006) On constitutive modelling of unsaturated soils. Acta Geotech 1:137-147

Gens A, Garitte B, Wileveau Y (2007) In situ behaviour of a stiff layered clay subject to thermal loading: observations and interpretation. Geotechnique 57:207-228

Gens A, Sanchez M, Guimaraes LDN, Alonso EE, Lloret A, Olivella S, Villar MV, Huertas F (2009) A full-scale in situ heating test for high-level nuclear waste disposal: observations, analysis and interpretation. Geotechnique 59:377-399

Gens A, Guimarães L, Olivella S, Sanchez M (2010) Modelling thermo-hydro-mechano-chemical interactions for nuclear waste disposal. J Rock Mech Geotech Eng 2:97-102

Gonzales S, Johnson KS (1984) Shale and other argillaceous strata in the United States. ORNL/Sub/84-64794/1, Oak Ridge National Laboratory, Oak Ridge, TN

Guimarães L, Gens A, Olivella S (2007) Coupled thermo-hydromechanical and chemical analysis of expansive clay subjected to heating and hydration. Transp Porous Media 66:341-372

Hansen FD, EL Hardin, RP Rechard et al. (2010) Shale disposal of U.S. high-level radioactive waste, SAND2010-2843, Sandia National Laboratories, Albuquerque, New Mexico

ITASCA (2009) FLAC3D V4.0, fast Lagrangian analysis of continua in 3-dimensions, user's guide. Itasca Consulting Group, Minneapolis, Minnesota

Karnland O, Muurinen A, Karlsson F (2005) Bentonite swelling pressure in $\mathrm{NaCl}$ solutions - experimentally determined data and model calculations. In: Alonso EE, Ledesma A (eds) Advances in understanding engineered clay barriers. Taylor \& Francis Group, London

Kristensson O, Åkesson M (2008) Mechanical modeling of MX-80quick tools for BBM parameter analysis. Phys Chem Earth Parts A/B/C 33(Supplement 1):S508-S515 
Laredj N, Missoum H, Bendani K (2010) Modeling the effect of osmotic potential changes on deformation behavior of swelling clays. J Porous Media 13:743-748

Meier P, Trick T, Blumling P, Volckaert G (2000) Self-healing of fractures within the EDZ at the Mont Terri Rock Laboratory: results after one year of experimental work. In: Proceedings of the international workshop on geomechanics, hydromechanical and thermomechanical behavior of deep argillaceous rocks: theory and experiments, 11-12 Oct 2000, Paris

NAGRA (2002) Project opalinus clay. Safety report. Demonstration of disposal feasibility for spent fuel, vitrified high-level waste and long-lived intermediate-level waste, TR 02-05

Ochs M, Lothenbach B, Shibata M, Yui M (2004) Thermodynamic modeling and sensitivity analysis of porewater chemistry in compacted bentonite. Phys Chem Earth Parts A/B/C 29:129-136

Patriarche D, Ledoux E, Simon-Coinçon R, Michelot J, Cabrera J (2004) Characterization and modeling of diffusion process for mass transport through the Tournemire argillites (Aveyron, France). Appl Clay Sci 26:109-122

Pruess K, Oldenburg C, Moridis G (2011) TOUGH2 user's guide, version 2.1, LBNL-43134 (revised), Lawrence Berkeley National Laboratory, Berkeley, California

Roscoe KH, Burland JB (1968) On the generalized stress-strain behaviour of the 'wet' clay. In: Heyman J, Leckic FA (eds) Engineering plasticity. Cambridge University Press, Cambridge, pp 535-609

Rutqvist J (2011) Status of the TOUGH-FLAC simulator and recent applications related to coupled fluid flow and crustal deformations. Comput Geosci 37:739-750

Rutqvist J, Wu Y-, Tsang C-, Bodvarsson G (2002) A modeling approach for analysis of coupled multiphase fluid flow, heat transfer, and deformation in fractured porous rock. Int J Rock Mech Min Sci 39:429-442

Rutqvist J, Ijiri Y, Yamamoto H (2011) Implementation of the Barcelona basic model into TOUGH-FLAC for simulations of the geomechanical behavior of unsaturated soils. Comput Geosci 37:751-762

Settari AT, Bachman AC, Walters DA (2005) How to approximate effects of geomechanics in conventional reservoir simulation. In: 2005 SPE annual conference and exhibition, Dallas, Texas, USA, 9-12 October, 2005

Thomas HR, He Y (1995) Analysis of coupled heat, moisture and air transfer in a deformable unsaturated soil. Geotechnique 45:677-689

van Genuchten MT (1980) A closed-form equation for predicting the hydraulic conductivity of unsaturated soils. Soil Sci Soc Am J 44:892-898

Xu T, Spycher N, Sonnenthal E, Zhang G, Zheng L, Pruess K (2011) TOUGHREACT version 2.0: a simulator for subsurface reactive transport under non-isothermal multiphase flow conditions. Comput Geosci 37:763-774

Zheng L, Samper J (2008) A coupled THMC model of FEBEX mockup test. Phys Chem Earth Parts A/B/C 33(Supplement 1(0)):S486

Zheng L, Samper J, Montenegro L, Fernández AM (2010) A coupled THMC model of a heating and hydration laboratory experiment in unsaturated compacted FEBEX bentonite. J Hydrol 386(1-4):80-94

Zheng L, Rutqvist J, Houseworth J, Davis R, Tinnacher L, Liu HH (2011) Investigation of near-field THMC coupled processes. Lawrence Berkeley National Laboratory, Berkeley 